Research Article

\title{
Flaw Imaging Technique for Plate-Like Structures Using Scanning Laser Source Actuation
}

\author{
Changgil Lee and Seunghee Park \\ Department of Civil and Environmental Engineering, Sungkyunkwan University, Cheoncheon-Dong, Jangan-Gu, Suwon, \\ Gyunggi-do 440-746, Republic of Korea
}

Correspondence should be addressed to Seunghee Park; shparkpc@skku.edu

Received 6 December 2012; Accepted 14 March 2013; Published 27 April 2014

Academic Editor: Gyuhae Park

Copyright (C) 2014 C. Lee and S. Park. This is an open access article distributed under the Creative Commons Attribution License, which permits unrestricted use, distribution, and reproduction in any medium, provided the original work is properly cited.

Recently, the longitudinal, shear, and surface waves have been very widely used as ultrasonic wave-based exploration methods to identify internal defects of host structures. In this context, a noncontact nondestructive testing (NDT) method is proposed to detect the damage of plate-like structures and to identify the location of the damage. To achieve this goal, a scanning laser source actuation technique is utilized to generate a guided wave and scans a specific area to find damage location more precisely. The ND:YAG pulsed laser is used to generate Lamb wave and a piezoelectric sensor is installed to measure the structural responses. The measured responses are analyzed using 3-dimensional Fourier transformation (3D FT). The damage-sensitive features are extracted by wavenumber filtering based on the 3D FT. Then, flaw imaging techniques of a plate-like structure are conducted using the damage-sensitive features. Finally, the plates with notches are investigated to verify the effectiveness and the robustness of the proposed NDT approach.

\section{Introduction}

Recently, there have been increasing demands on structural 2 health monitoring (SHM) and nondestructive testing (NDT) in the fields of civil, mechanical, and aerospace engineering and so on to prevent losses of life and property by continuously monitoring the systems. Especially, local monitoring methodologies have been studied to overcome the limitation of global monitoring techniques [1-4]. Effective SHM/NDT methods must be intuitive so that inspection results can be easily understandable and must have high throughput [5]. To tackle this issue, a lot of researches based on acoustic and ultrasonic technologies have been proposed using laser interferometry, laser vibrometer, pulsed laser, and so on because the ultrasonic waves are sensitive to the mechanical properties of structures, while the wave responses are hardly affected by radiation [5]. Holography based imaging technique, one of the full-field ultrasonic wave imaging techniques, requires highly diffusive target surface. Also, holographic images can be obtained clearly in dark environments, and hence this method is not suitable to remote automatic inspection although this has noncontact inspection capability [6]. Dynamic responses can be collected by laser Doppler vibrometry which measures vibrational velocity of target structures. Although the performance of the laser Doppler vibrometry is improved in terms of scan angles and automatic focusing [7], it has still disadvantage that retroreflective film should be attached on target surfaces to improve signal-to-noise ratio when a scanning head is located far from the target [8-10]. In contrast, laser interferometry, which also senses vibration responses of target structures, works well without the retroreflective film, but its performance has not been proved when the distance between scanning head and target surface is greater than $0.5 \mathrm{~m}[11,12]$. To overcome these drawbacks, a laser beam pulse can be used to generate ultrasonic waves. The laser beam pulse can provide many advantages including fast wave generation with low pulse energy, high spatial resolution, inspection ability on complex target, and so on [5]. 


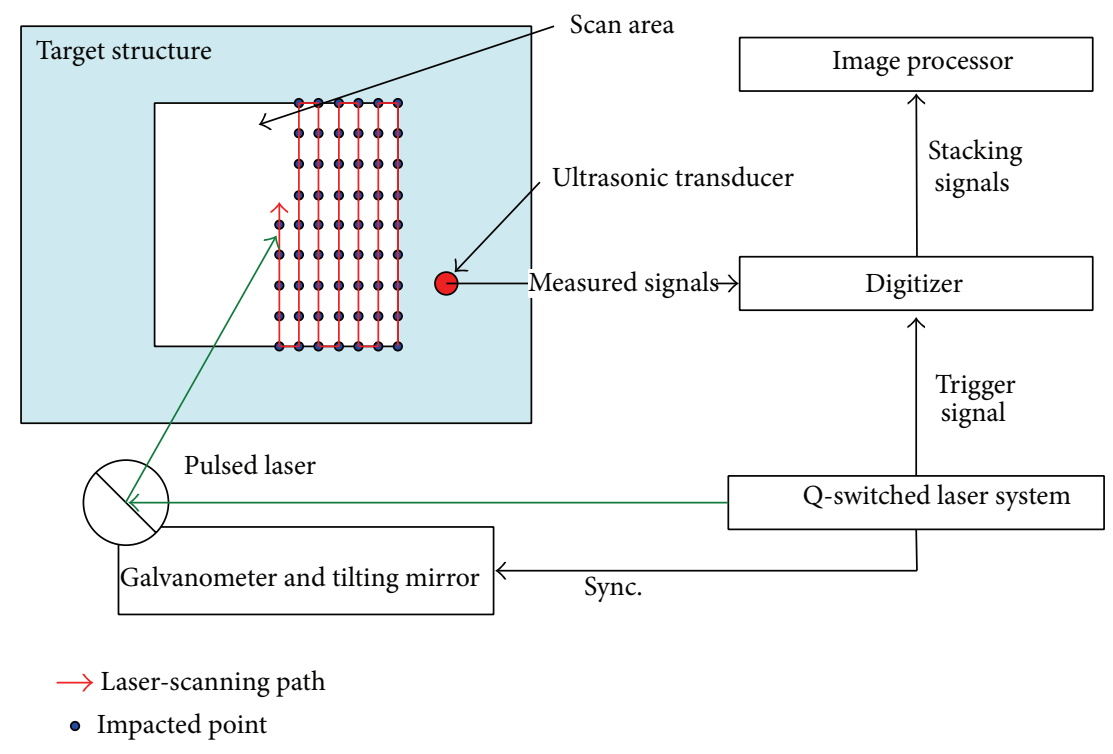

FIGURE 1: A scheme of an ultrasonic wave propagation imaging system based on a UWPI laser system.

(1) Measure time-domain responses

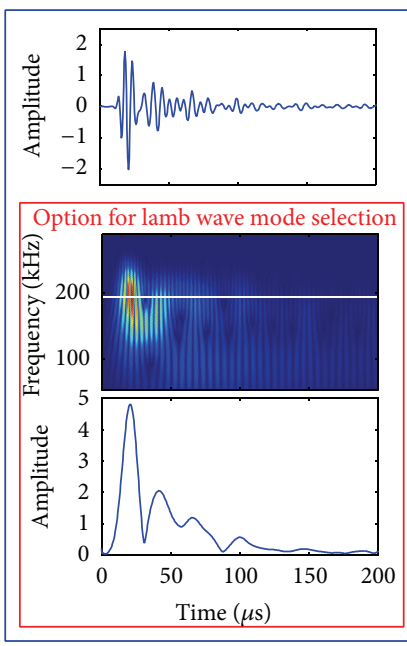

(2) Stack the measured signals

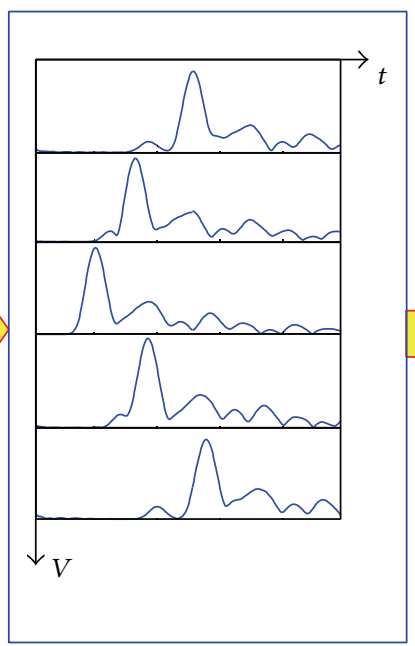

(3) Slice the stacked signals along time axis

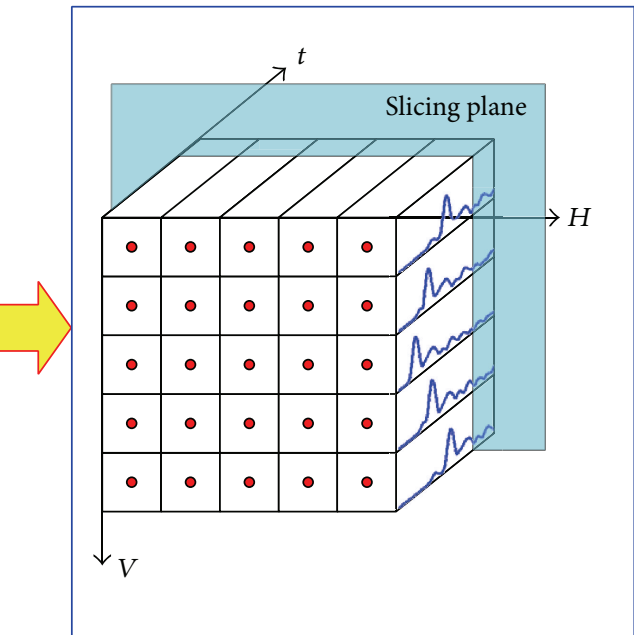

FIGURE 2: A scheme of an ultrasonic wave propagation imaging algorithm.

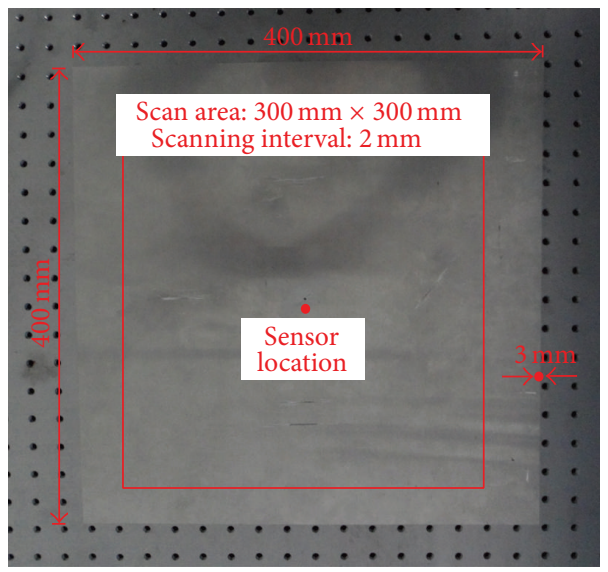

FIGURE 3: An aluminum plate and scanning information. 


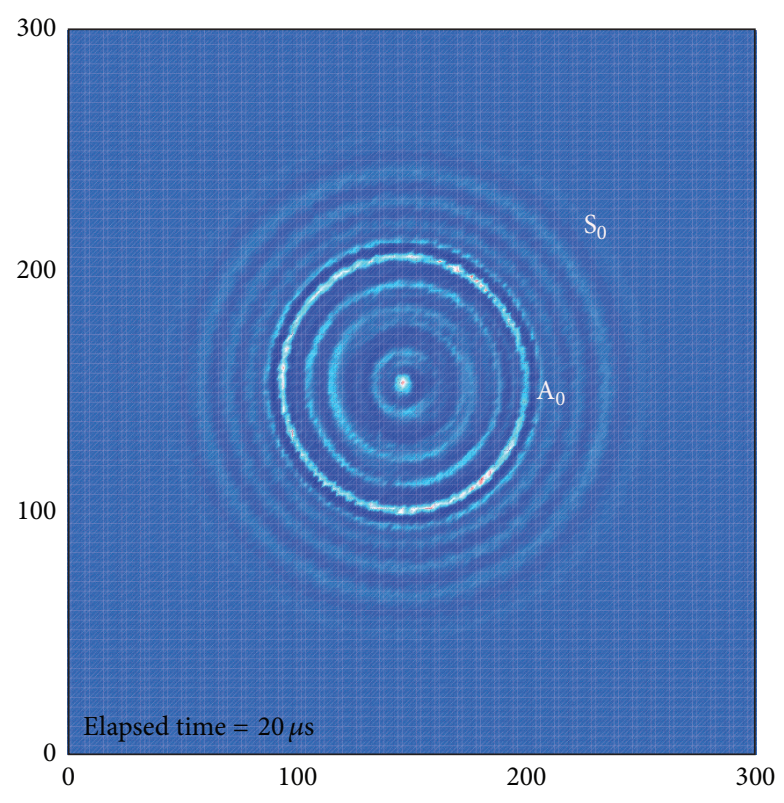

FIGURE 4: UWPI snapshot at $20 \mu \mathrm{s}$.

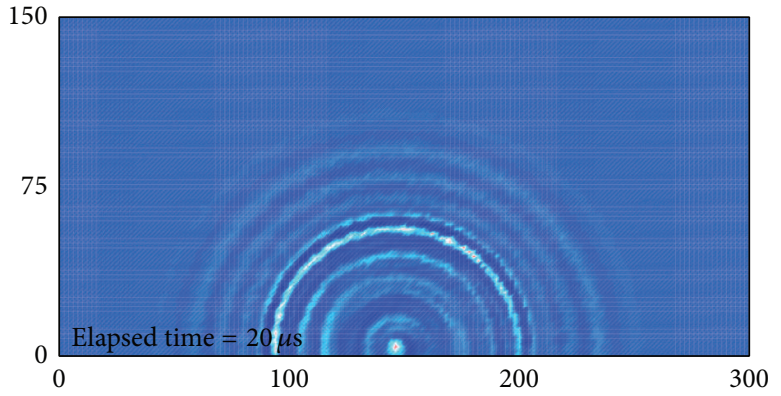

(a) Incident waves before filtering

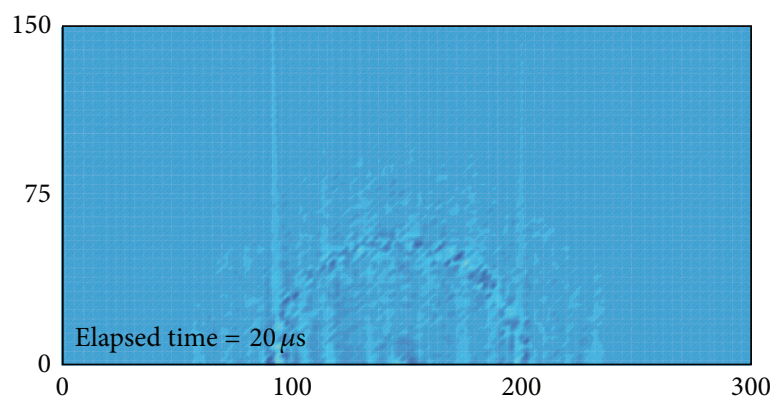

(c) Incident waves after filtering

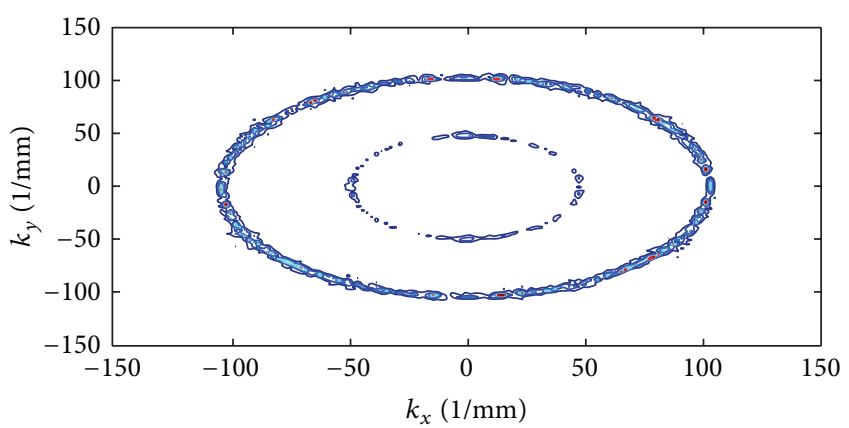

(b) 3D FT before filtering

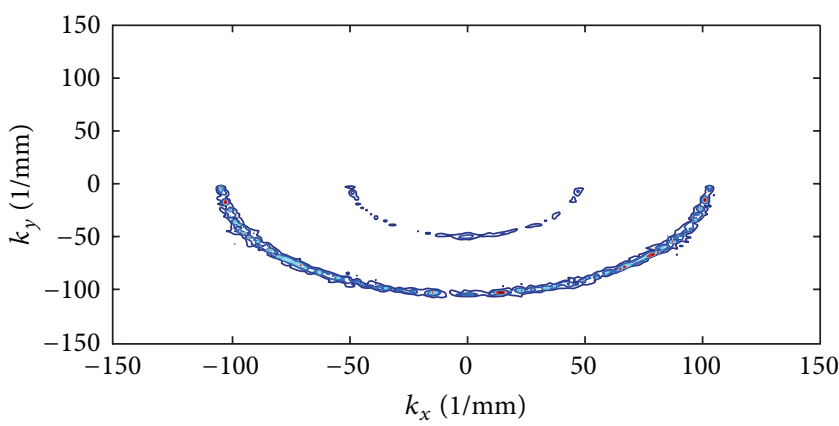

(d) 3D FT after filtering

FIGURE 5: Elimination of upward incident waves by wavenumber filtering.

In this paper, ultrasonic wave propagation is visualized using ND:YAG pulsed laser and a flaw image is constructed based on wavenumber filtering and root mean square (RMS). The ND:YAG pulsed laser is used to generate Lamb wave and a piezoelectric sensor is installed to measure the structural responses. The measured responses are analyzed using $3 \mathrm{D}$ FT and then the damage-sensitive features are extracted by wavenumber filtering and RMS [13, 14]. Then, flaw imaging technique of a plate-like structure is conducted using the damage-sensitive features. Finally, the plate with a notch is 


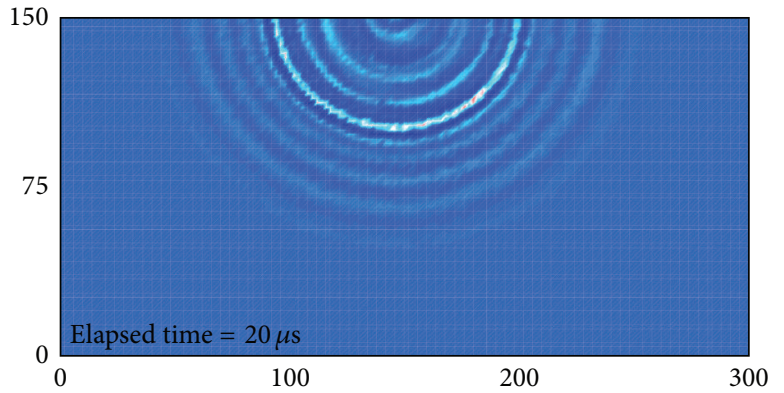

(a) Incident waves before filtering

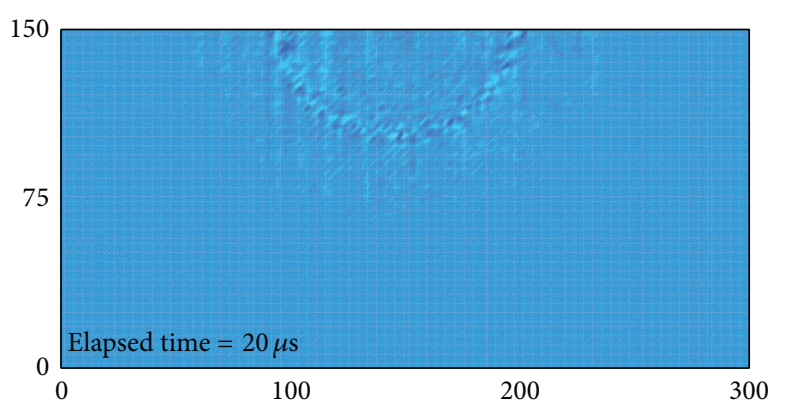

(c) Incident waves after filtering

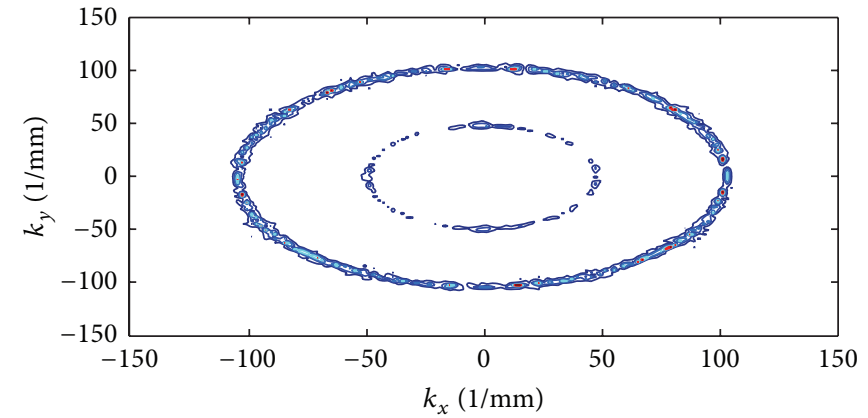

(b) 3D FT before filtering

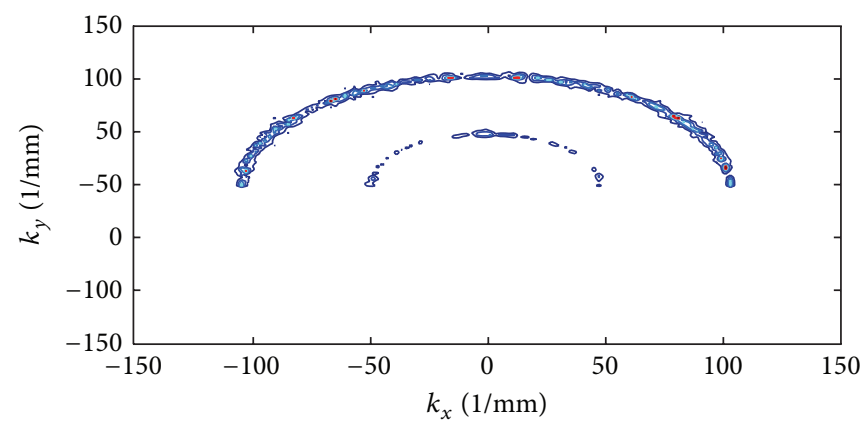

(d) 3D FT after filtering

FIGURE 6: Elimination of downward incident waves by wavenumber filtering.

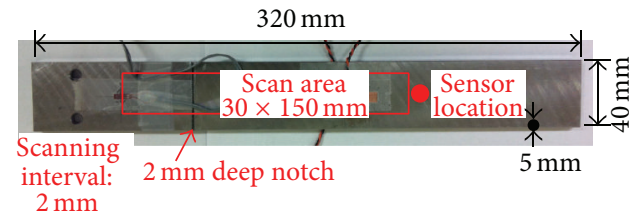

Figure 7: Configuration of a specimen with a notch (target to detect).

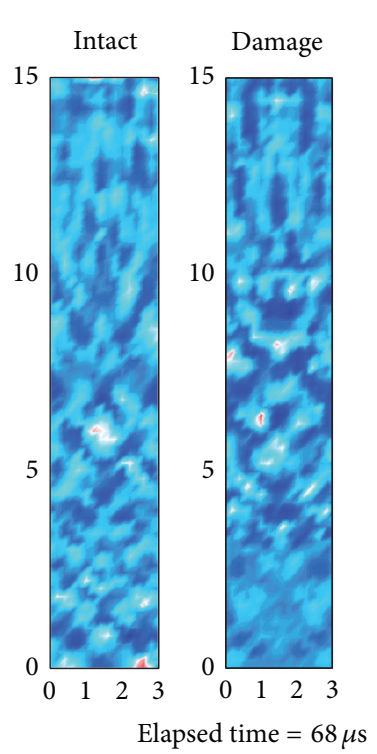

(a) Before filtering

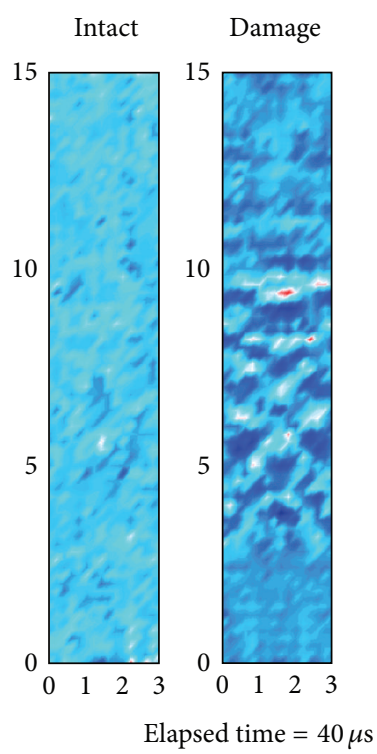

(b) After filtering

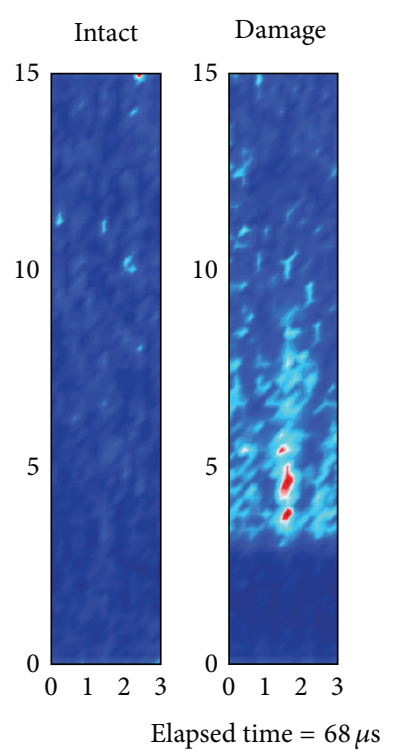

(c) RMS image after filtering

FIGURE 8: Visualization of the guided wave propagation and flaw image. 


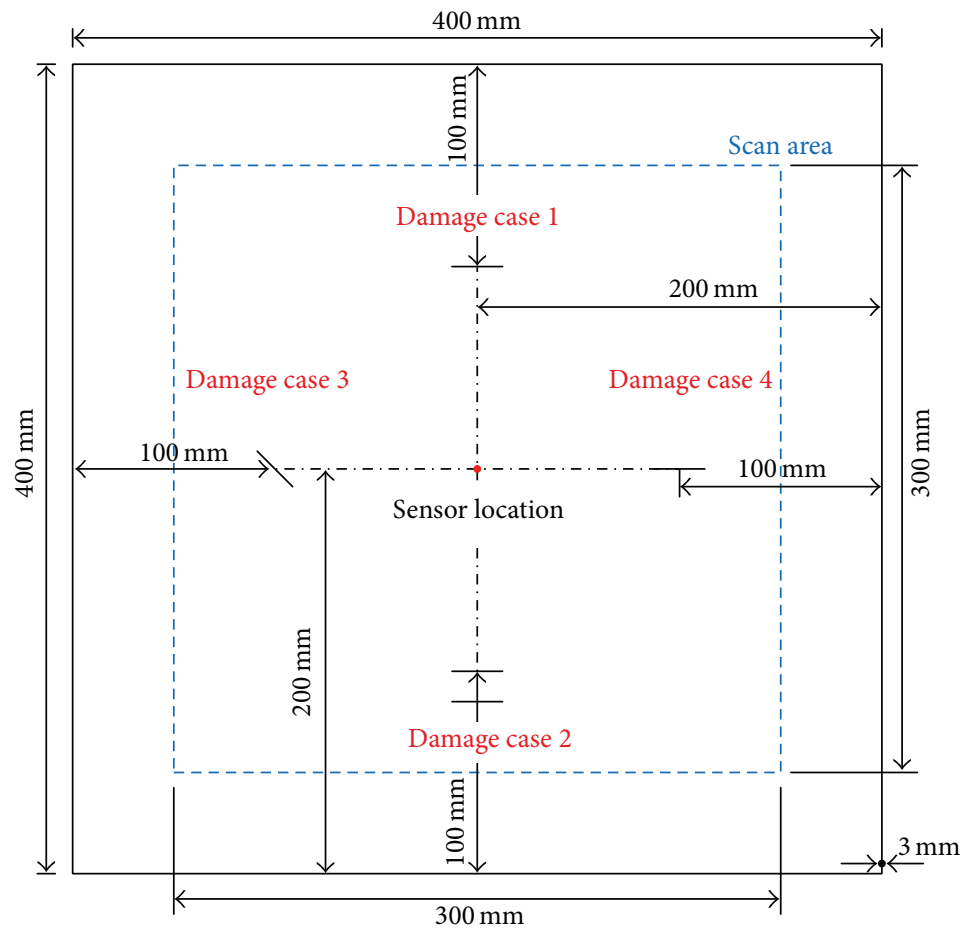

Figure 9: Damage cases: case 1: tangential to wave front, case 2: tangential to wave front (two damages), case 3: an angle of 45 degrees with wave front, and case 4: perpendicular to wave front; dotted line indicates the scan area.

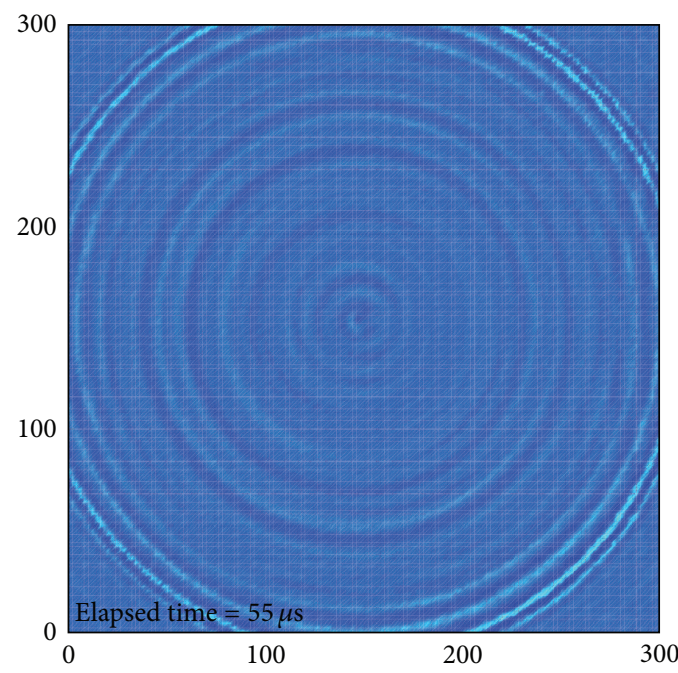

(a) Intact condition

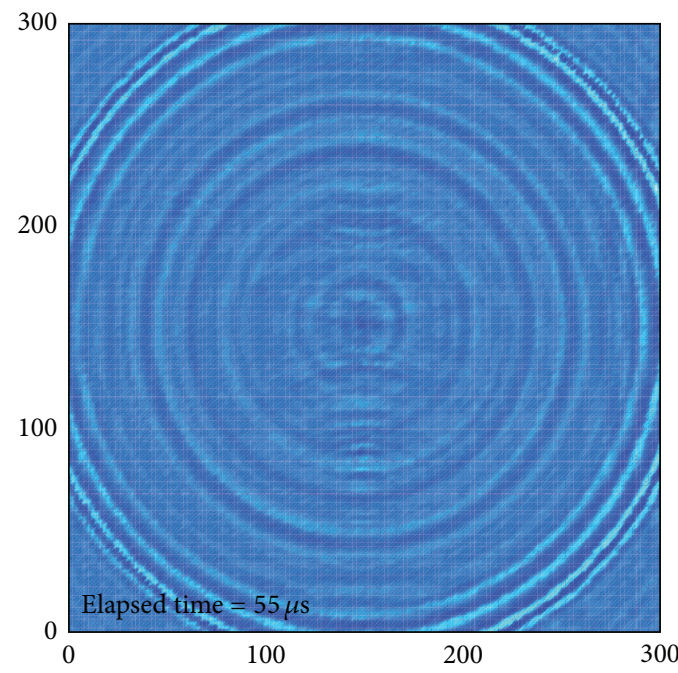

(b) Damage condition

FIGURE 10: Comparison of UWPI snapshots at $55 \mu \mathrm{s}$.

investigated to verify the effectiveness and the robustness of the proposed NDT approach.

\section{Ultrasonic Wave Propagation Imaging System}

Ultrasonic wave propagation imaging (UWPI) system consists of a Q-switched laser system, a laser mirror scanner based on galvanometer, an ultrasonic sensor, a high-speed digitizer, and an image processor, which was rearranged referring the previous works [5] as shown in Figure 1. Qswitched Nd:YAG diode-pumped solid-state laser is used for the pulsed laser system, which has the wave length of $1064 \mathrm{~nm}$ and maximum pulse repetition frequency of $20 \mathrm{~Hz}$ [15]. The pulsed laser beam impacts a specific point on a target structure by the laser mirror scanner which is designed so that two galvanometers are operated at the wave length 


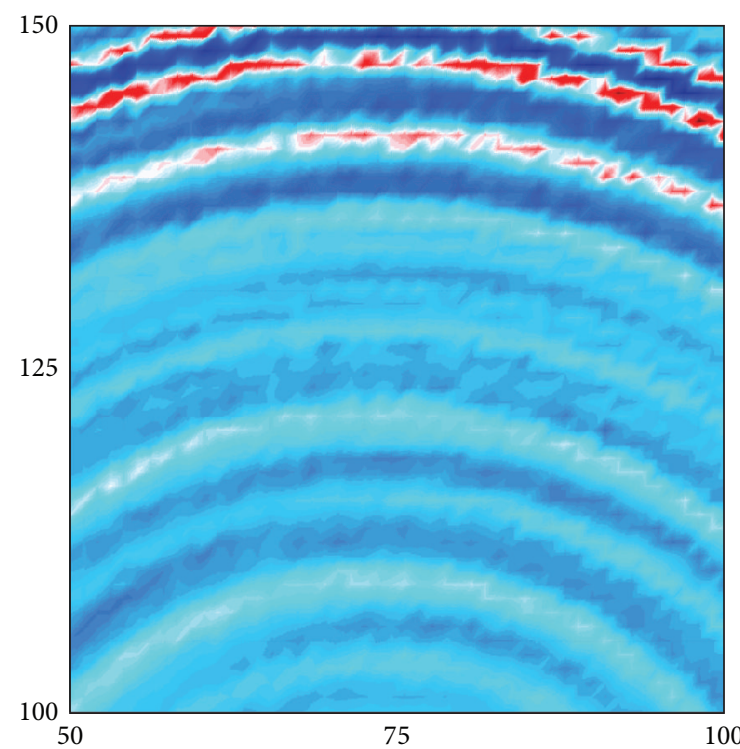

(a) Intact image before filtering

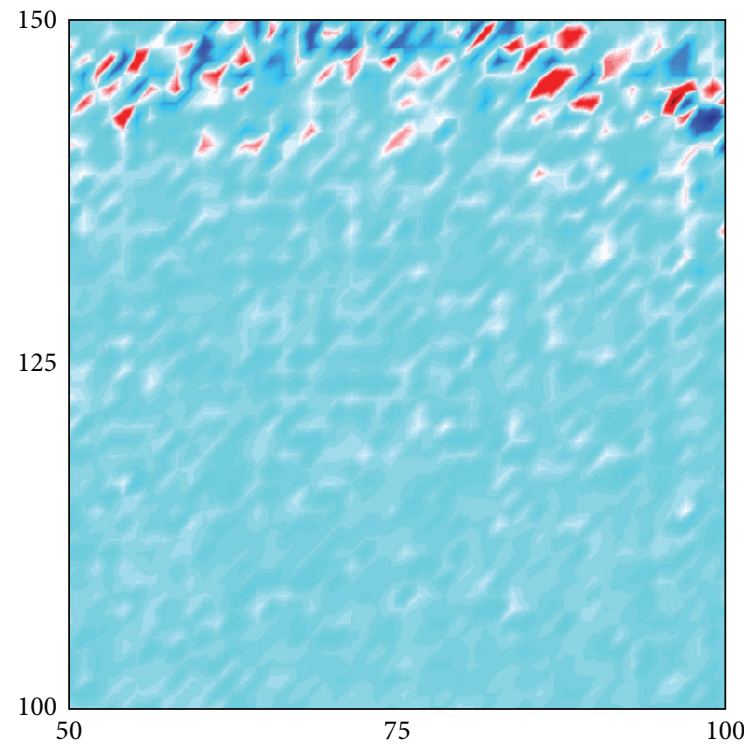

(c) Intact image after filtering

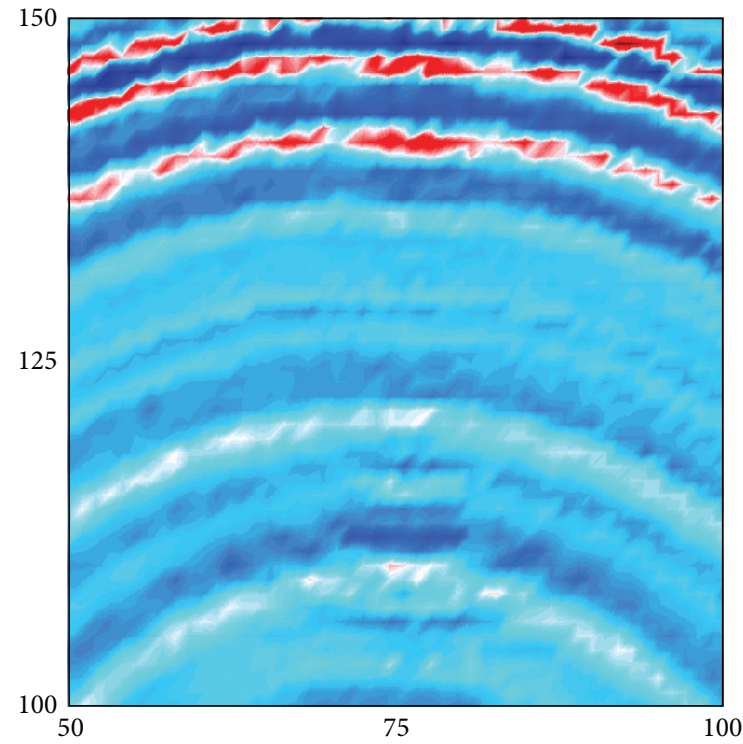

(b) Damaged image before filtering

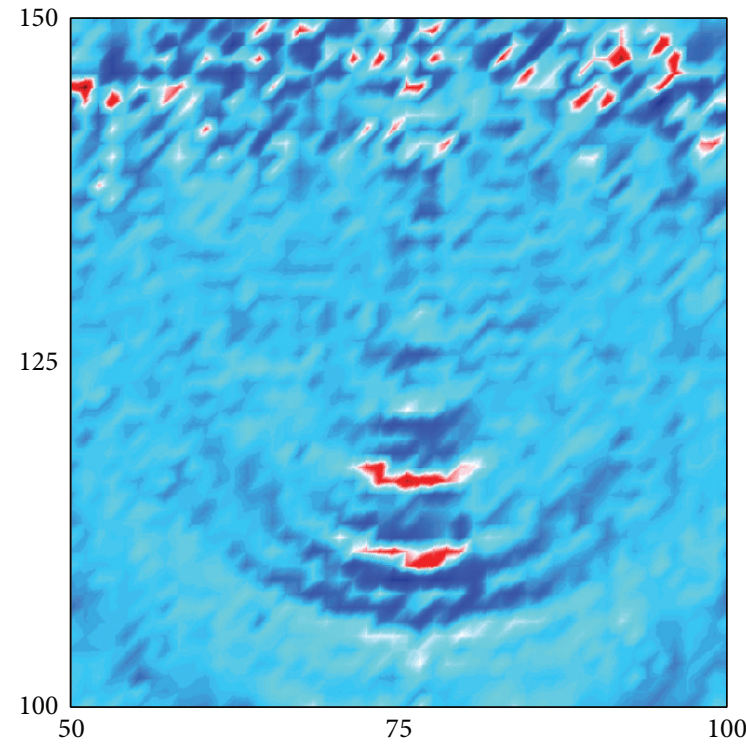

(d) Damaged image after filtering

FIGURE 11: Comparison of UWPI snapshots at $48 \mu$ s for damage case 1.

of $1064 \mathrm{~nm}$. The operating angles of the galvanometers are orthogonal to each other so that the laser beam can scan 2-dimensional area rapidly. Additionally, maximum angular velocity of the galvanometer is $100 \mathrm{rad} / \mathrm{s}$ within $\pm 0.35 \mathrm{rad}$. The laser beam reflected at the laser mirror scanner is focused on the target structure by a f-theta lens which is installed at the end of the laser mirror scanner. In this study, the f-theta lens is designed so that the distance between the laser mirror scanner and the target structure is $2 \mathrm{~m}$. First, the focused laser beam scans the target structure vertically upward and the laser beam steps horizontally leftward after vertical scanning. Then the laser beam scans vertically downward as shown in Figure 1. Therefore, the scanning laser beams generate a grid of the laser impingement points and the pitch of the grid can be adjusted by the control algorithm of the laser system.

When the pulsed laser beams impact the target structure, ultrasonic waves are generated by thermoelastic mechanism and propagated. The multiple wave responses can be measured by only single PZT attached to the backside or the front side of the structure. The measured time signals are placed at each laser impinging point and the UWPI is obtained as shown in Figure 2. As in Figure 2, wave propagation is visualized with 3 steps. (i) Measuring and filtering signals: to improve signals-to-noise ratio, a pass-band filter is applied. Additionally, specific modes of the ultrasonic waves can be optionally extracted by wavelet transform. In this study, 


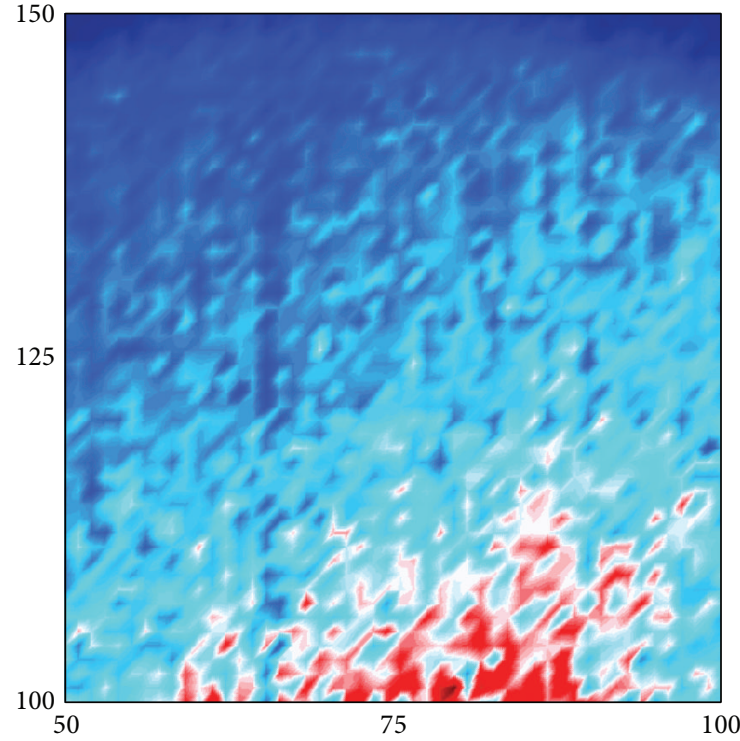

(a) Intact RMS image before filtering

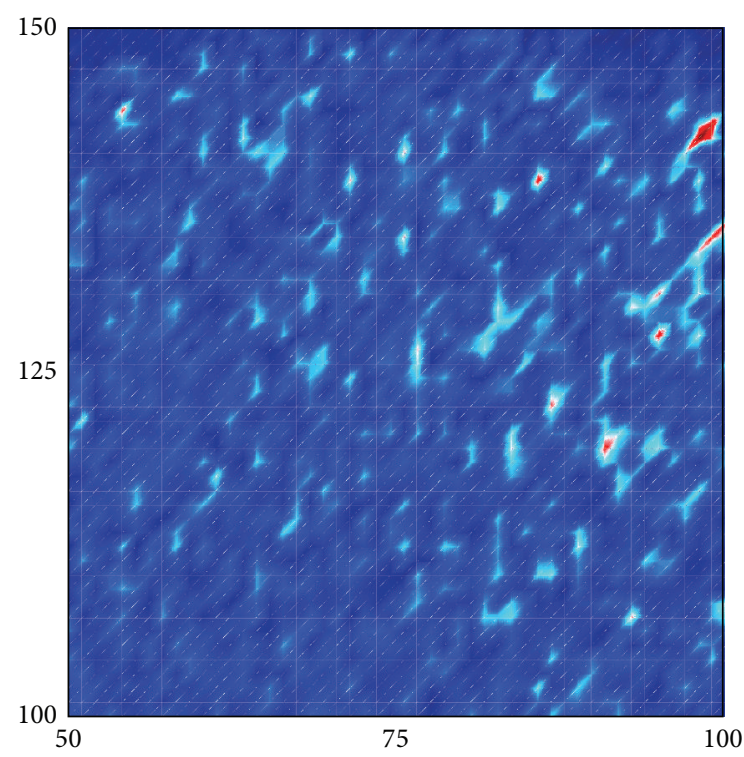

(c) Intact RMS image after filtering

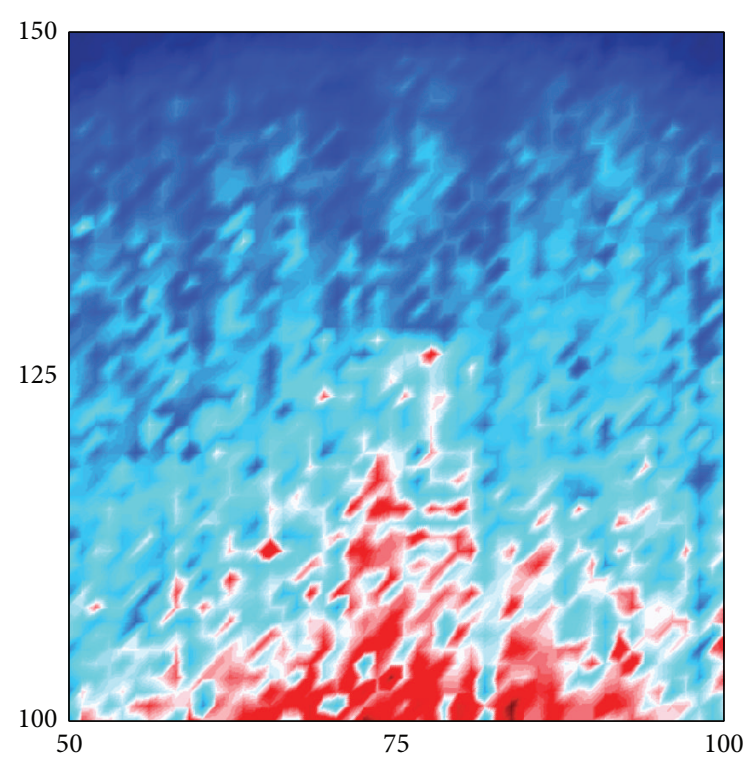

(b) Damaged RMS image before filtering

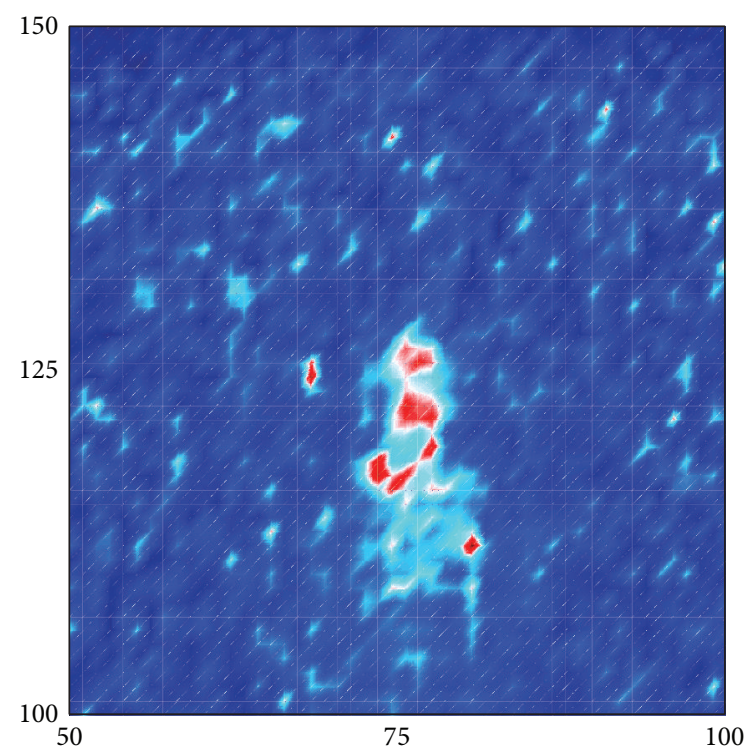

(d) Damaged RMS image after filtering

FIGURE 12: Comparison of RMS snapshots at $48 \mu$ s for damage case 1.

however, wavelet transform is not conducted. (ii) Placing the processed signals to the laser impinging points: the signal group results in a 3D space with respect to horizontal, vertical, and time axes. (iii) Slicing the 3D space along the time axis: finally, the wave propagation image can be obtained by slicing repeatedly within measuring period [5].

\section{Flaw Imaging Algorithm}

The flaw images can be easily obtained by observing reflected waves from damage after eliminating strong incident waves. To filter out the incident waves, wavenumber filtering concept is applied in this study. First, the wave propagation image is transformed from time/space domain to frequency/wavenumber domain by 3D Fourier transform as described in [13]

$$
W\left(k_{x}, k_{y}, \omega\right)=\iiint_{-\infty}^{\infty} w(x, y, t) e^{-\left(\omega t+k_{x} x+k_{y} y\right)} d x d y d t,
$$

where $w(x, y, t)$ is $2 \mathrm{D}$ wave signals in time domain $k_{x}, k_{y}$, and $\omega$ are wavenumber with respect to $x$ and $y$ axes and angular frequency, respectively.

The incident waves can be filtered out by eliminating positive or negative side of the frequency/wavenumber domain signals using window function as shown in (2). If a structure contains a flaw, the incident waves are scattered at the damage, 


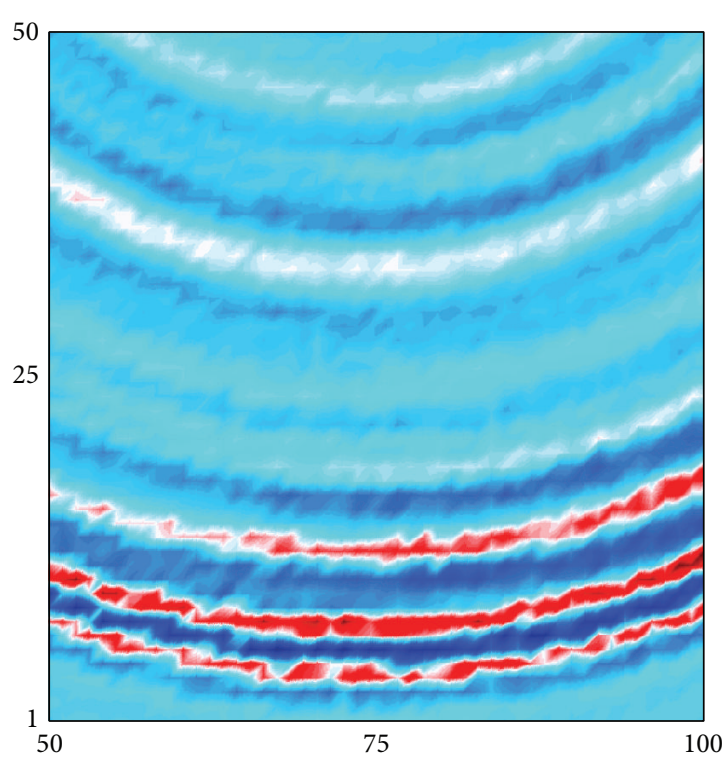

(a) Intact image before filtering

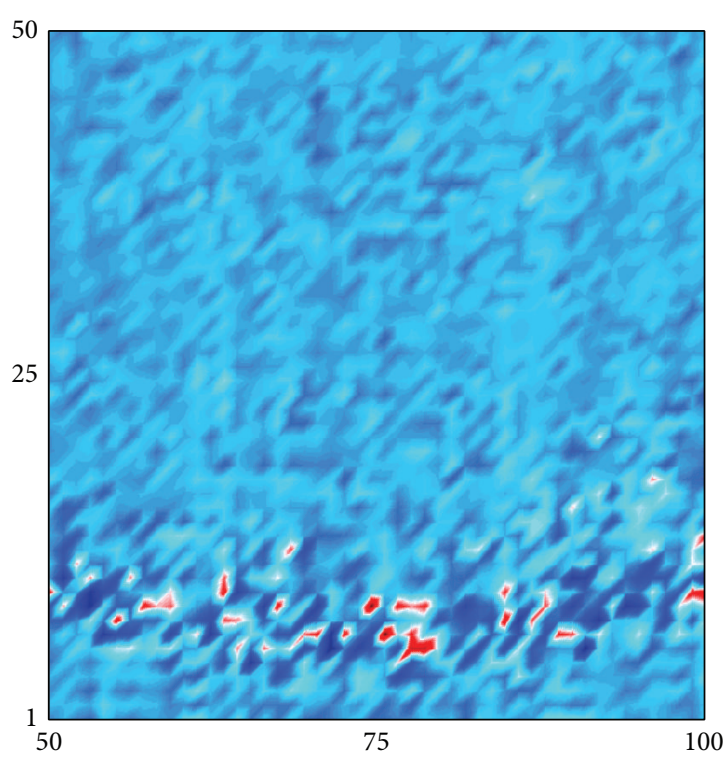

(c) Intact image after filtering

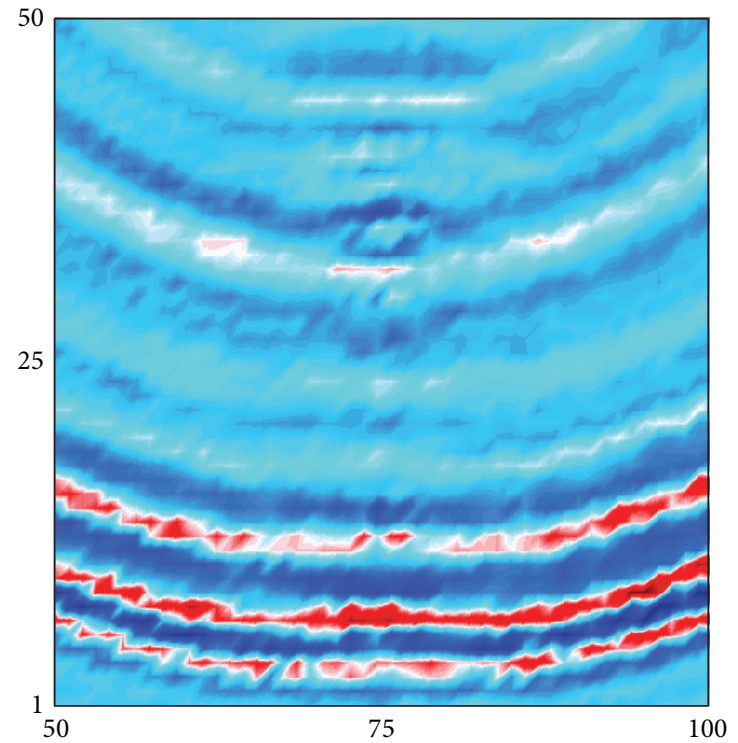

(b) Damaged image before filtering

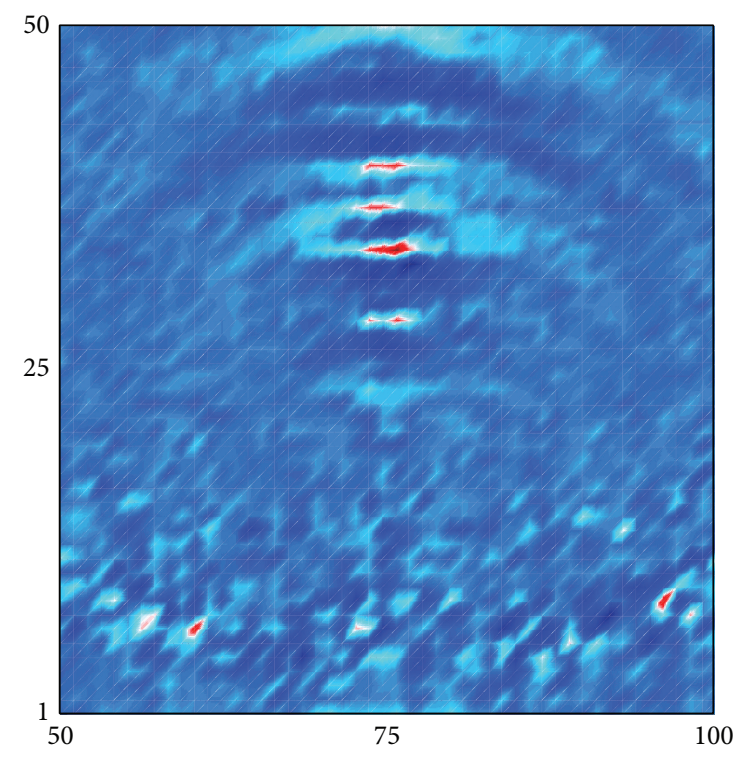

(d) Damaged image after filtering

FIGURE 13: Comparison of UWPI snapshots at $48 \mu$ s for damage case 2.

and hence the reflections due to only damage can be extracted by the wavenumber filtering:

$$
\bar{W}\left(k_{x}, k_{y}, \omega\right)=W\left(k_{x}, k_{y}, \omega\right) U\left(k_{x}, k_{y}, \omega\right)
$$

where $\bar{W}\left(k_{x}, k_{y}, \omega\right)$ is filtered data, $W\left(k_{x}, k_{y}, \omega\right)$ is UWPI data, and $U\left(k_{x}, k_{y}, \omega\right)$ is the window function for filtering. In this study, a rectangular function is used for the window function.

The filtered UWPI data is inversely transformed from wavenumber and frequency domain to spatial and time domain. In the next section, this process is described using some figures. Finally, damage can be quantified by calculating root mean square (RMS) values using the filtered signals as shown in [14]

$$
w_{S}^{r}(x, y)=\left[\frac{1}{T} \int_{0}^{T}\left(w^{r}(x, y, t)\right)^{2} d t\right]^{1 / 2},
$$

where $T$ is the period of the measured signals and $w^{r}(x, y, t)$ is the reflected signals.

\section{Experimental Study}

4.1. Preliminary Test Using an Aluminum Plate. First, an intact aluminum plate was scanned to verify the feasibility of the UWPI system. A 6061T aluminum alloy was used 


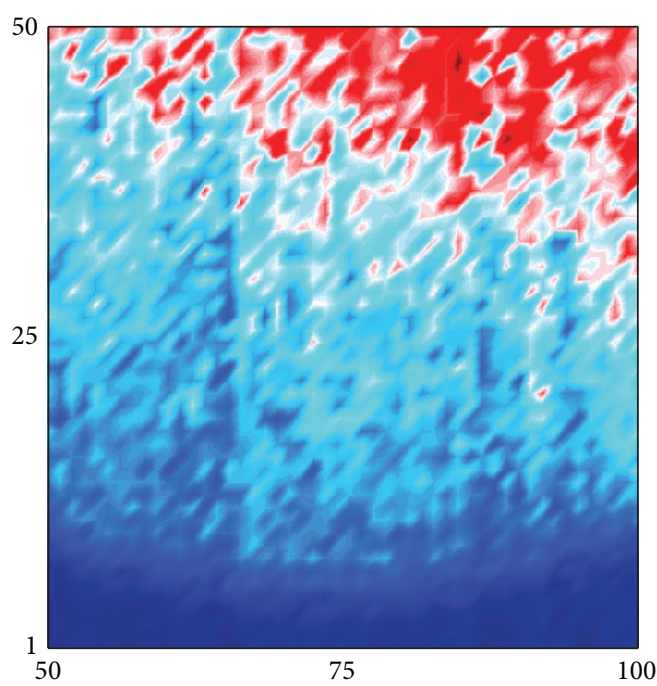

(a) Intact RMS image before filtering

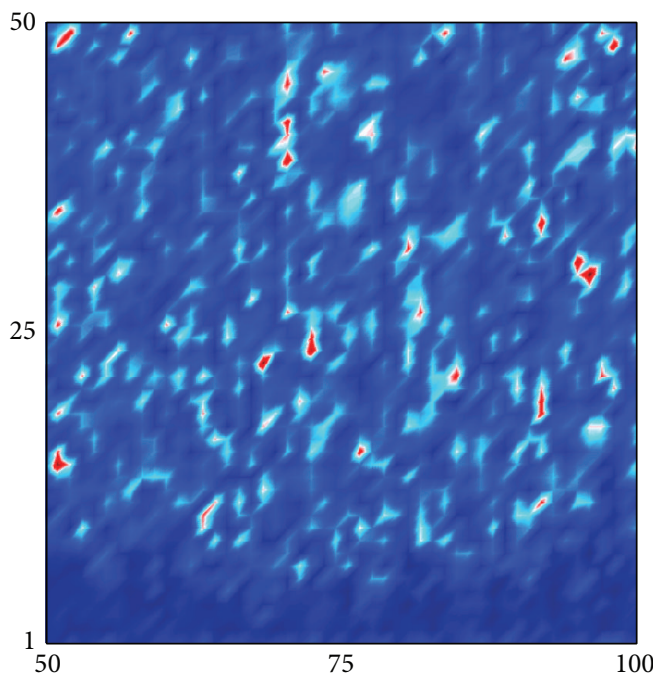

(c) Intact RMS image after filtering

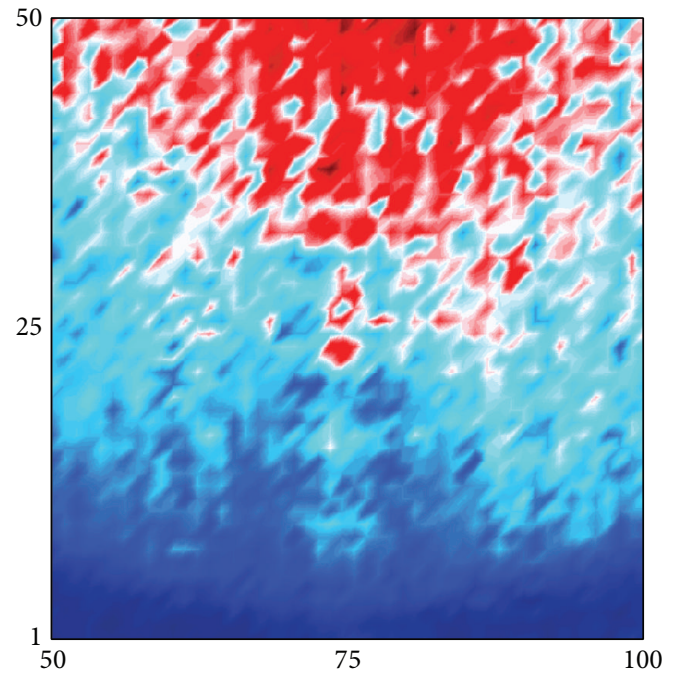

(b) Damaged RMS image before filtering

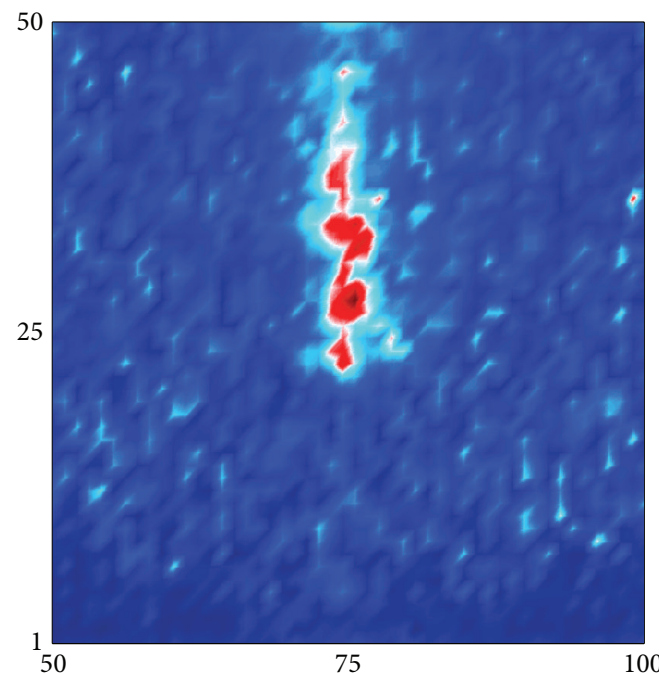

(d) Damaged RMS image after filtering

FIGURE 14: Comparison of RMS snapshots at $48 \mu$ s for damage case 2.

for the test as shown in Figure 3. The dimension of the plate was $400 \mathrm{~mm} \times 400 \mathrm{~mm}$ with the thickness of $3 \mathrm{~mm}$. Scanned area was $300 \mathrm{~mm} \times 300 \mathrm{~mm}$ at the center of the plate with the scanning interval of $2 \mathrm{~mm}$, and hence $151 \times$ 151 grid was generated. To measure multiple wave responses, an amplifier-integrated acoustic emission sensor (hereafter, AE sensor) was attached to the backside of the plate to avoid interference of the laser impact. The sensor has a broadband characteristic with lower and higher cutoff frequencies of $100 \mathrm{kHz}$ and $2 \mathrm{MHz}$, respectively. The resonant frequency of the sensor is $200 \mathrm{kHz} \pm 20 \%$ and the maximum sensitivity is $120 \pm 3 \mathrm{~dB}$ at the resonant frequency. The laser mirror scanner was installed $2 \mathrm{~m}$ apart from the plate.

Using the UWPI system, the snapshot of the UWPI at $20 \mu \mathrm{s}$ is depicted in Figure 4. The amplitude of $\mathrm{S}_{0}$ mode of the propagating waves is much smaller than that of $A_{0}$ mode as show in Figure 4. The group velocities of each mode were about $5.51 \mathrm{~km} / \mathrm{s}$ for $S_{0}$ mode and $3.031 \mathrm{~km} / \mathrm{s}$ for $A_{0}$ mode which were calculated from the UWPI snapshot. The velocities were very close to those from theoretical dispersion curves which were $5.5 \mathrm{~km} / \mathrm{s}$ for $\mathrm{S}_{0}$ mode and $3.03 \mathrm{~km} / \mathrm{s}$ for $\mathrm{A}_{0}$ mode. Therefore, it can be noted that the UWPI system is well operated.

Next, wavenumber filtering process based on 3D Fourier transform is shown in Figures 5 and 6 . The frequency component representing the maximum amplitude of the wave responses was $186 \mathrm{kHz}$, which is within the range of the resonant frequency of the sensor. Therefore, wavenumber data was obtained at $186 \mathrm{kHz}$. To eliminate the incident waves, 3D FT data was multiplied by rectangular window as shown 


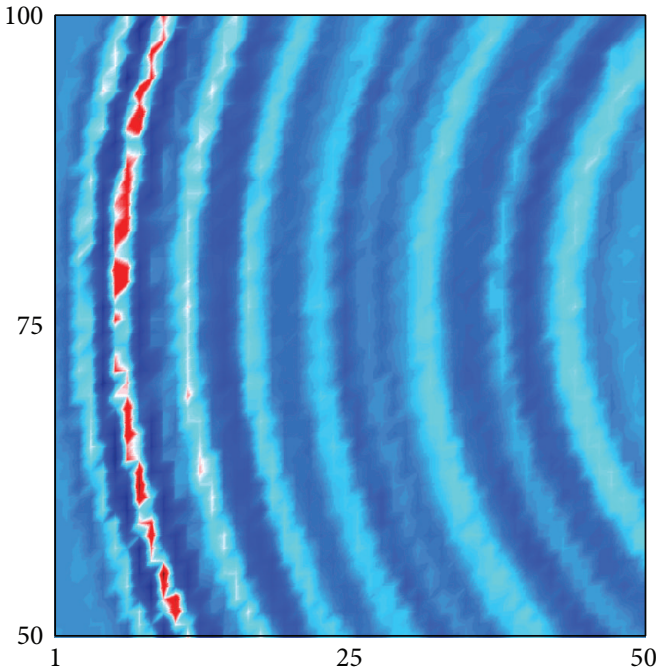

(a) Intact image before filtering

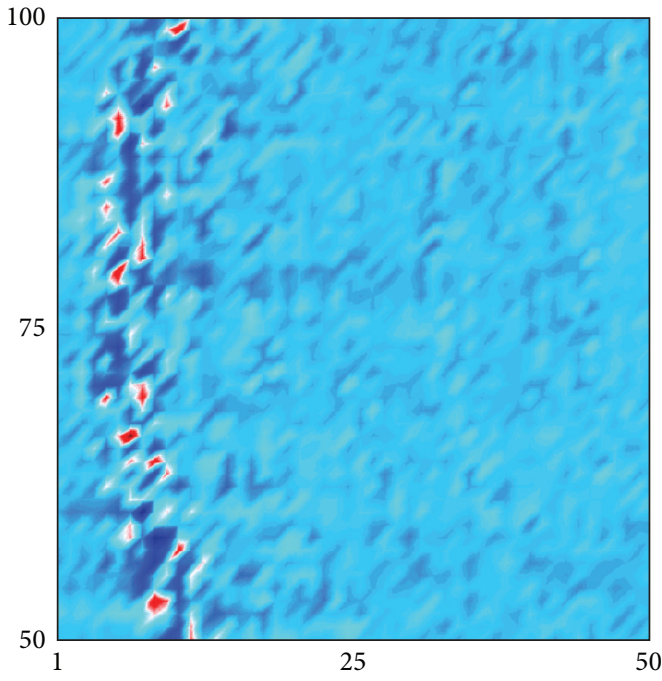

(c) Intact image after filtering

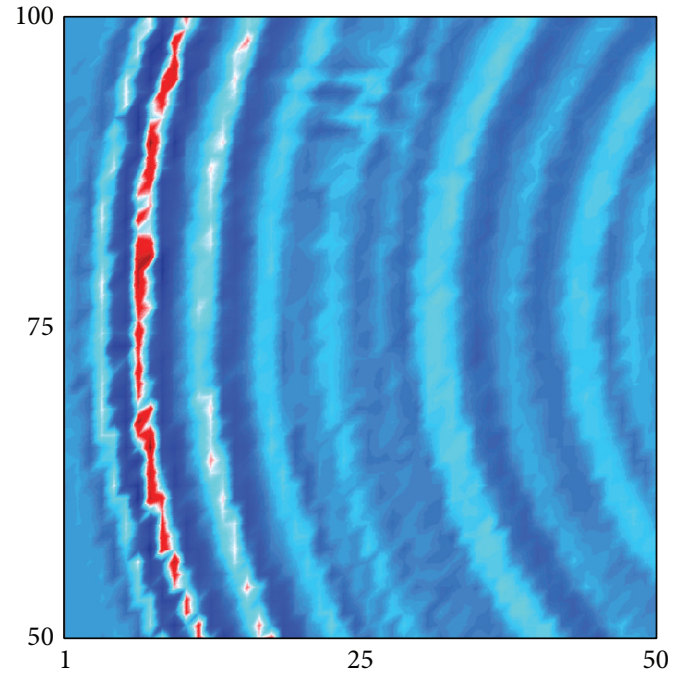

(b) Damaged image before filtering

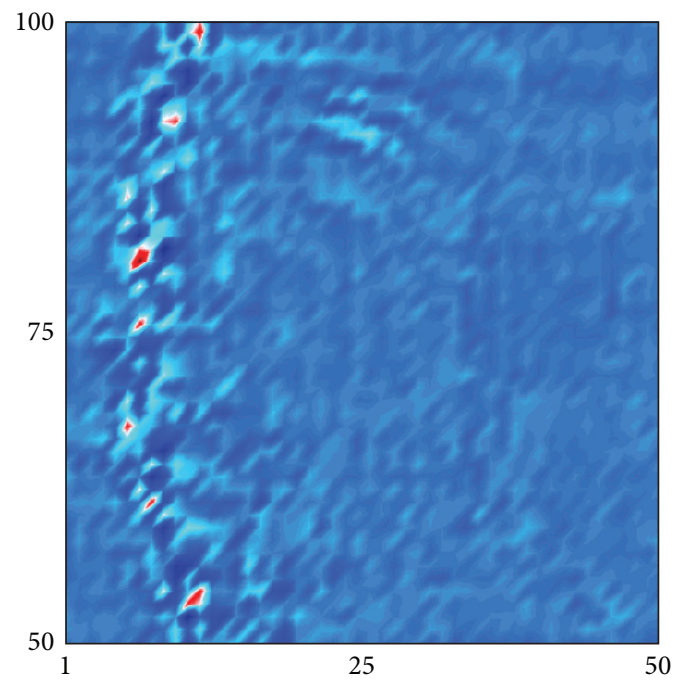

(d) Damaged image after filtering

FIGURE 15: Comparison of UWPI snapshots at $46 \mu$ s for damage case 3.

in Figures 5(d) and 6(d). After the wavenumber filtering, both upward and downward incident waves were clearly filtered out as in Figures 5(c) and 6(c).

4.2. Damage Detection Using a Steel Coupon. A steel coupon with a notch was used to verify the proposed method as shown in Figure 7. Scan area was $30 \mathrm{~mm} \times 150 \mathrm{~mm}$ with the scanning interval of $2 \mathrm{~mm}$. The $\mathrm{AE}$ sensor was attached to the backside of the laser impinging point and the sensing point was not in the scan area as shown in Figure 7. The target damage was the $2 \mathrm{~mm}$ deep notch which was formed at the same side with the sensor.

The UWPI image is complex before wavenumber filtering due to incident waves, reflections from side boundaries, and the notch as shown in Figure 8(a). Although the shape of the UWPI image is complex, the continuity is marginally observed for the damage case as shown in Figure 8(a). Next, the forward signals were filtered out by the wavenumber filtering and only reflections are more distinguishable than the image obtained from raw data as shown if Figure 8(b). Finally, the discontinuity is dramatically detected from the RMS values of the filtered signals as shown in Figure 8(c) and it can be noted that the notch is successfully detected.

4.3. Damage Detection Using an Aluminum Plate. For next damage detection test, a 6061T aluminum plate was used again, which had same size as in Figure 3. Four types of notches were artificially formed as shown in Figure 9: (i) case 1: one tangential notch to incident wave front, (ii) case 2: two tangential notches to the incident wave front, which were $20 \mathrm{~mm}$ apart from each other, (iii) case 3: one diagonal notch to the incident wave front with an angle of 45 degrees, and (iv) case 4: one perpendicular notch to the incident wave front. All of the notches were $2 \mathrm{~mm}$ deep, $1 \mathrm{~mm}$ wide, and $20 \mathrm{~mm}$ 


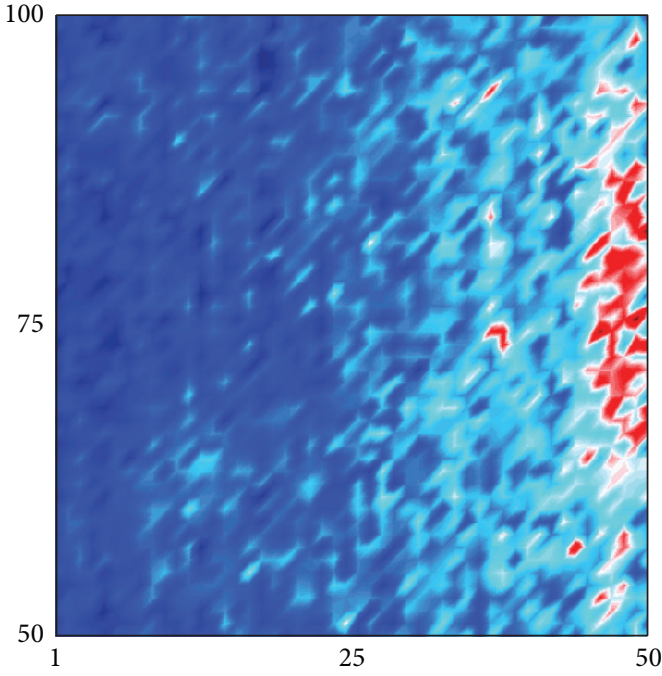

(a) Intact RMS image before filtering

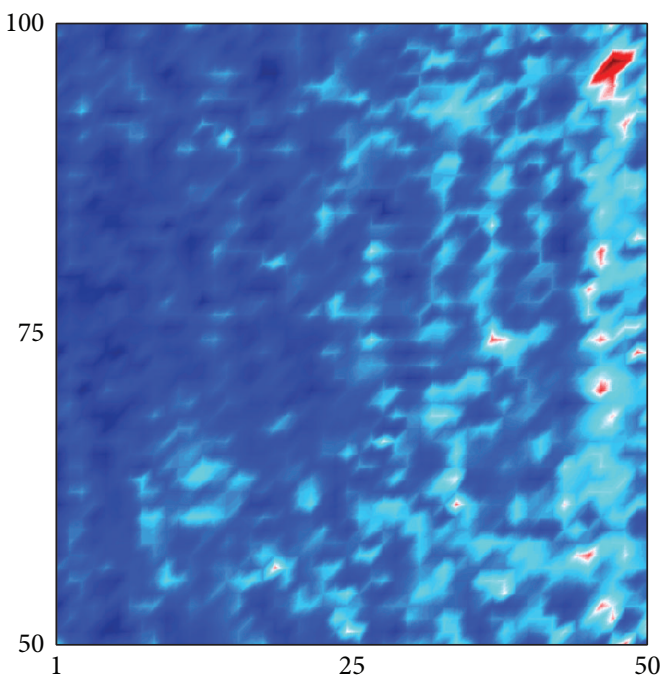

(c) Intact RMS image after filtering

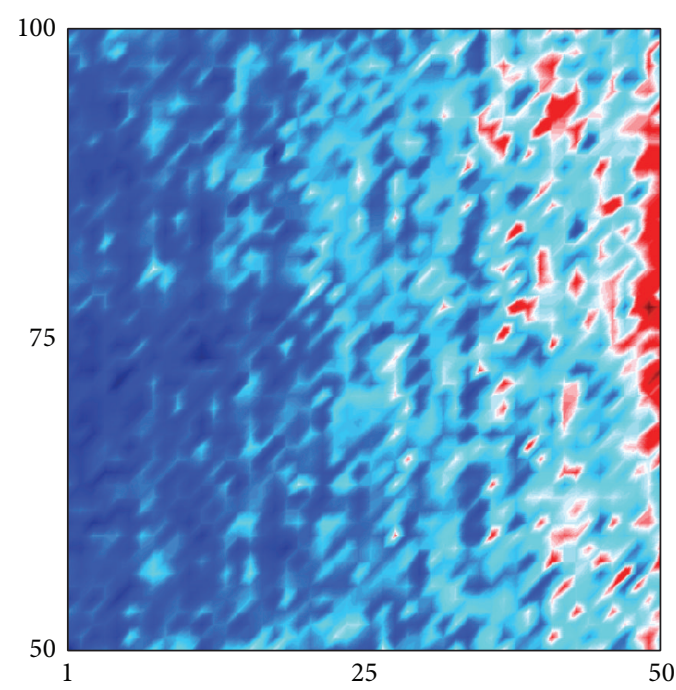

(b) Damaged RMS image before filtering

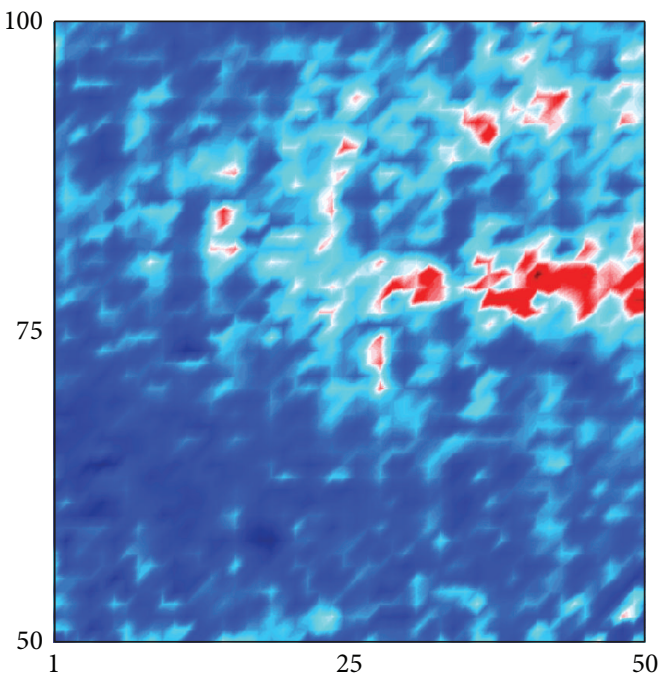

(d) Damaged RMS image after filtering

FIGURE 16: Comparison of RMS snapshots at $130 \mu$ s for damage case 3 .

long. Scan area was same as in Figure 3 and UWPI snapshots at $55 \mu \mathrm{s}$ are plotted as in Figure 10 so that reflected waves from boundaries cannot be observed. In the damaged plate, reflected waves from the damages are detected and hence the location of the damages can be approximated as show in Figure 10(b).

Next, areas near the damages are zoomed in and flaw imaging process is conducted in those areas. First, intact and damaged images at $48 \mu$ s are shown in Figure 11 before and after wavenumber filtering for damage case 1. In Figure 11(b), reflected waves from the damage are distinguishable from incident waves, while only incident waves are observed in Figure 11(a). After the wavenumber filtering, the incident waves were eliminated and hence only reflected waves are plotted in Figure 11(d).

Then, RMS values were calculated at $48 \mu$ s using the UWPI images before and after the wavenumber filtering.
A flaw is not clearly observed before filtering regardless of damage as shown in Figures 12(a) and 12(b). However, damage is clearly evaluated at point $(75,125)$ as shown in Figure 12(d) compared to Figure 12(c).

Next, the UWPI and flaw images for damage case 2 are considered. The patterns of the images are similar to damage case 1. In this case, two notches were created and hence the transmitted waves through the first damage were reflected at the second damage. Therefore, the shape of the reflections is more complicated than those from damage case 1 as shown in Figure 13(d).

In Figure 14, RMS images are plotted. The flaw images are not clear before filtering regardless of damage as shown in Figures 14(a) and 14(b). After the wavenumber filtering, the flaw is clearly visualized at the point $(75,25)$ as shown in Figure 14(d). However, unfortunately, the pattern of the flaw image is the same as the image for the damage case 1 


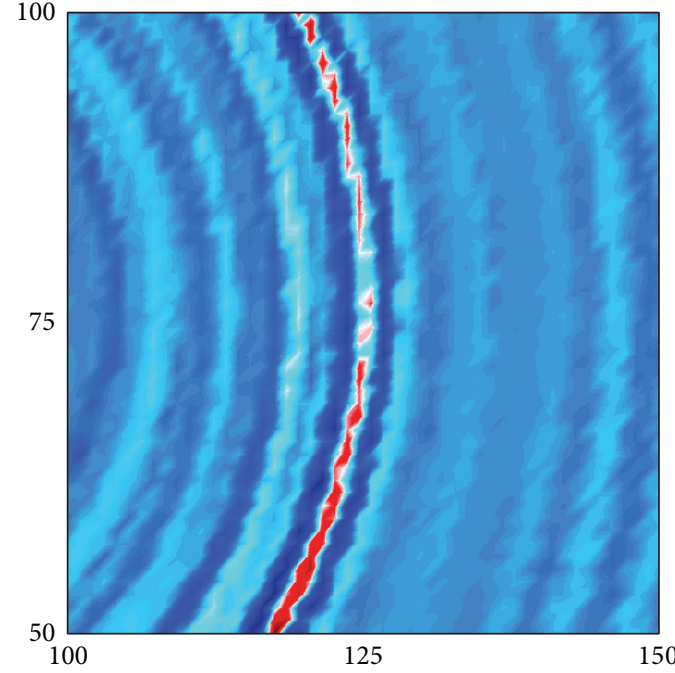

(a) Intact image before filtering

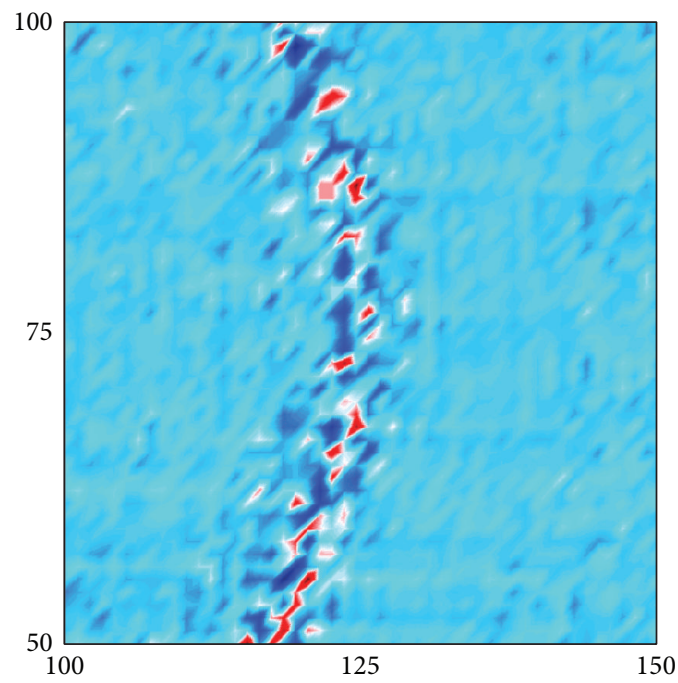

(c) Intact image after filtering

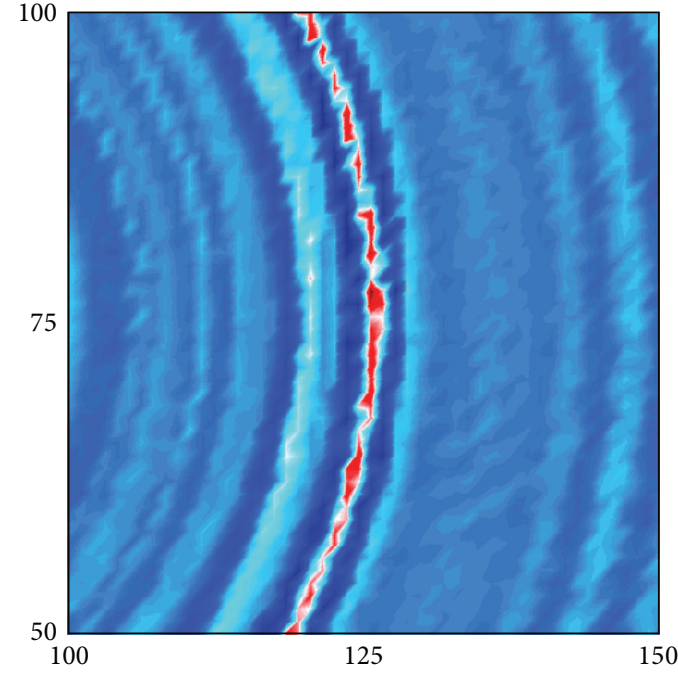

(b) Damaged image before filtering

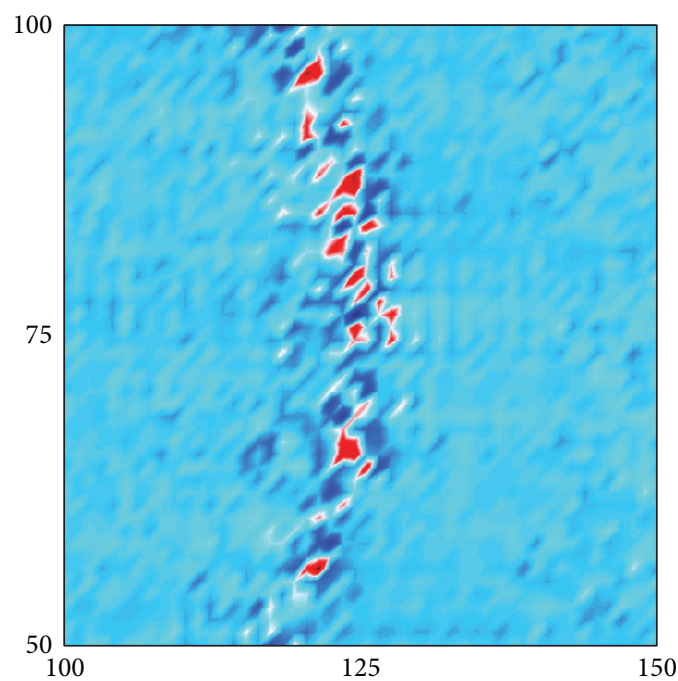

(d) Damaged image after filtering

FIgURE 17: Comparison of UWPI snapshots at $35 \mu$ s for damage case 4.

and hence two damages can be identified as one damage. This might be because the direction of the transmitted waves through the first damage is same as the direction of the incident waves.

In the case of damage 3, reflected waves from the damage are observed, but the energy level of those is much low because the damage is inclined to the incident wave front as shown in Figure 15.

In this case, RMS images were obtained at relatively longer period than the previous two cases to use reflections from boundary. As results, the damage is visualized as shown in Figure 16(d). Since the damage was inclined to the wave front, the waves were partially reflected. Additionally, the waves were filtered along horizontal axis (or vertical axis) using the wavenumber filtering and hence the damage could not be clearly detected.
The final case is on the perpendicular damage to the incident wave front. In Figure 17(b), the waves are scattered both upward and downward at the damage. In this case, the energy level of the scattered waves is low even after the wavenumber filtering in a similar manner to case 3 because the damage is perpendicular to the incident wave front.

RMS images are also obtained at relatively longer period so that the reflected waves from the corner of the plate can arrive at the damage as show in Figure 18. In this case, also, the damage can be identified if the flaw image is compared to the RMS image from the intact data because of the orientation of the damage.

In this case, the damage could not be also clearly shown in a similar manner with case 3 . Additionally, the damage was perpendicular to the wave front, the filter is applied horizontally, and hence the damage could be observed at 


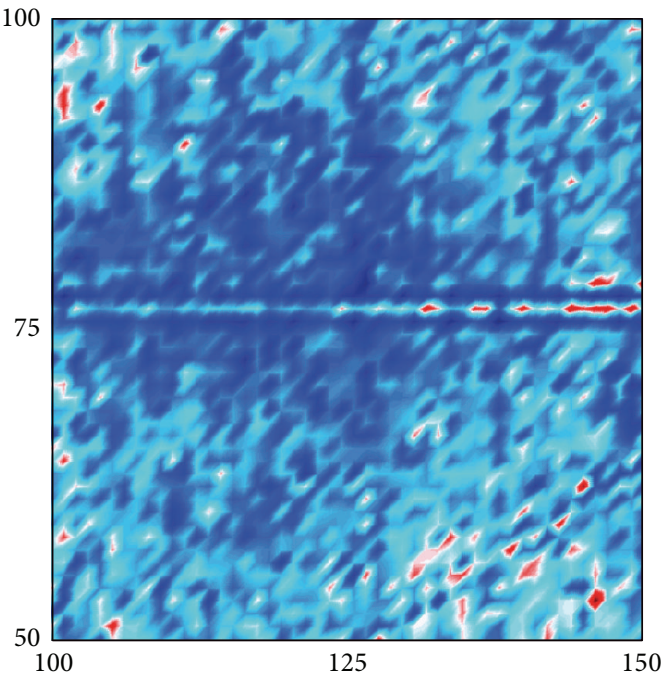

(a) Intact RMS image before filtering

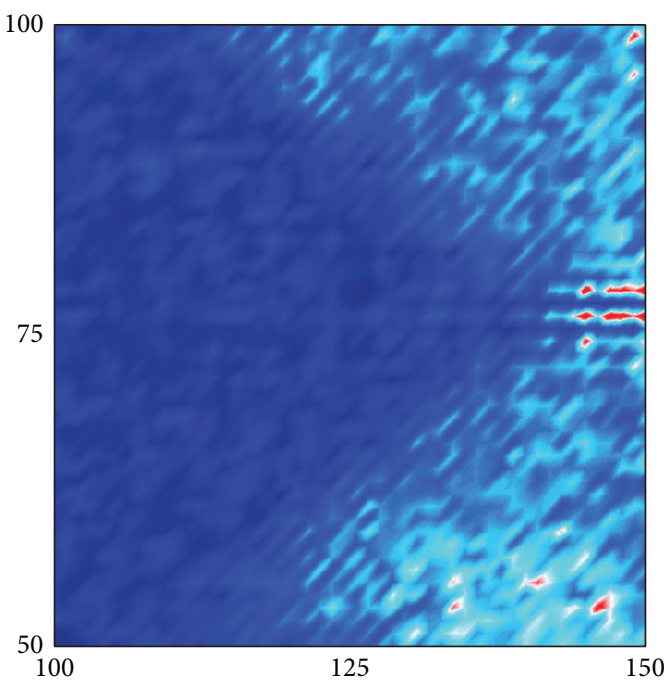

(c) Intact RMS image after filtering

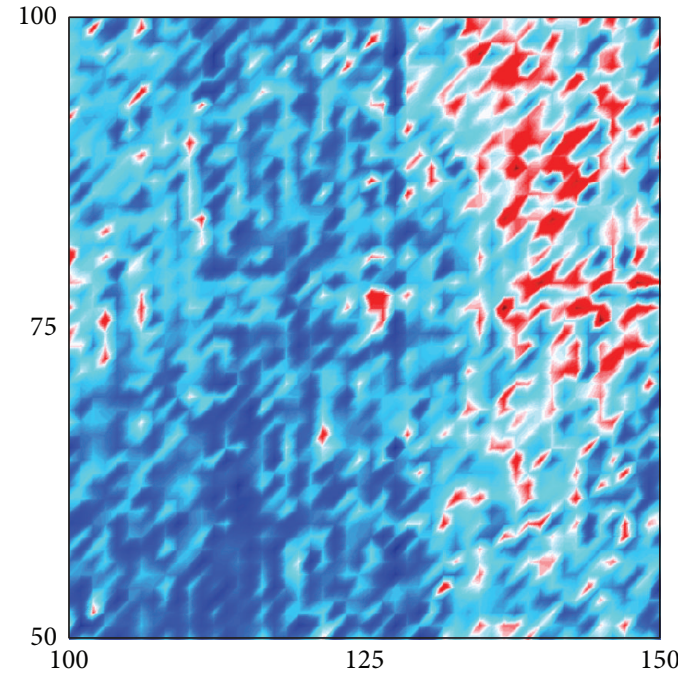

(b) Damaged RMS image before filtering

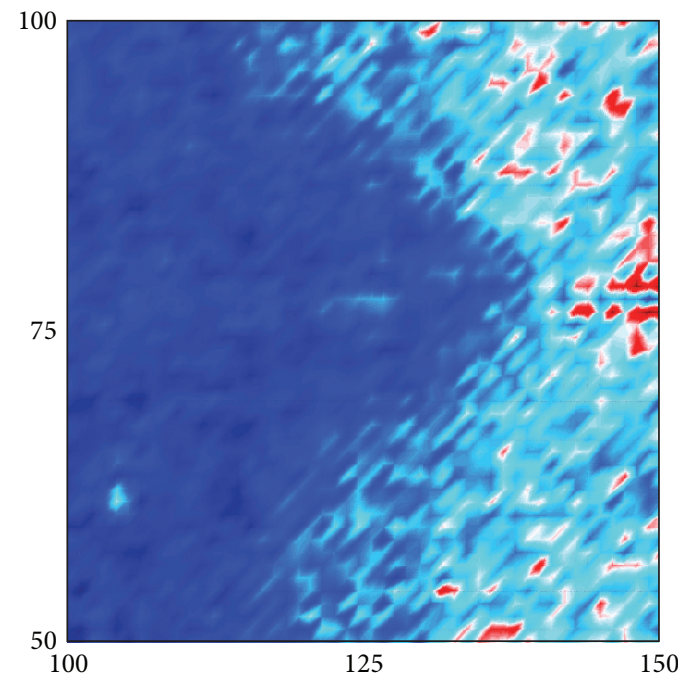

(d) Damaged RMS image after filtering

FIGURE 18: Comparison of RMS snapshots at $155 \mu$ s for damage case 4.

the longer period of the data to consider the effect of the reflected waves from the boundaries. However, the damage could not be clearly detected because the reflections from the boundaries were attenuated as depicted in Figure 18(d).

\section{Conclusion}

In this paper, the ultrasonic wave propagation imaging system and flaw imaging technique were proposed based on ND:YAG pulsed laser system and wavenumber filtering. To verify the feasibility of the proposed technique, two steps of damage detection test were conducted. First, a notch in a steel coupon was detected and then various types of damages were identified in an aluminum plate. The notch in the steel coupon was successfully detected by eliminating incident waves and by calculating root mean square, although the shape of the propagating waves was complicated due to the narrow width of the specimen. On the other hand, the damages in the aluminum plate were partially detected. The tangential damages to the incident wave front were successfully identified, while the inclined and perpendicular damages to the incident wave front were visible when the flaw images were compared to the intact images. It could be caused by the sparse scanning grid, the window for the wavenumber filtering, and the filtering direction. Therefore, further research is now ongoing to investigate the detectable size of the flaw and to detect various damages clearly. Additionally, other types of structures will be scanned to verify the applicability of the proposed method.

\section{Conflict of Interests}

The authors declare that there is no conflict of interests regarding the publication of this paper. 


\section{Acknowledgments}

This study was supported by Basic Science Research Program (2010-0023404) through the National Research Foundation (NRF) of Korea, the Nuclear Research \& Development of the Korea Institute of Energy Technology Evaluation and Planning (KETEP) Grant funded by the Ministry of Knowledge Economy of Korea government (no. 2011T100200161), the research project Development of Patch/Implant System based on IT Technology for Safe Management of Large ScaleStructure funded by the Ministry of Knowledge Economy of Korea Government. This all-out support is greatly appreciated.

\section{References}

[1] S. Park, J.-W. Kim, C. Lee, and S.-K. Park, "Impedance-based wireless debonding condition monitoring of cfrp laminated concrete structures," NDT \& E International, vol. 44, no. 2, pp. 232-238, 2011.

[2] C. Lee and S. Park, "Damage classification of pipelines under water flow operation using multi-mode actuated sensing technology," Smart Materials and Structures, vol. 20, no. 11, Article ID 115002, 9 pages, 2011.

[3] J. Min, S. Park, C.-B. Yun, C.-G. Lee, and C. Lee, "Impedancebased structural health monitoring incorporating neural network technique for identification of damage type and severity," Engineering Structures, vol. 39, pp. 210-220, 2012.

[4] C. Lee and S. Park, "De-bonding detection on a CFRP laminated concrete beam using self sensing-based multi-scale actuated sensing with statistical pattern recognition," Advances in Structural Engineering, vol. 15, no. 6, pp. 919-927, 2012.

[5] J. R. Lee, C. C. Chia, H. Jin Shin, C. Y. Park, and D. Jin Yoon, "Laser ultrasonic propagation imaging method in the frequency domain based on wavelet transformation," Optics and Lasers in Engineering, vol. 49, no. 1, pp. 167-175, 2011.

[6] R. E. Green Jr., "Non-contact ultrasonic techniques," Ultrasonics, vol. 42, no. 1-9, pp. 9-16, 2004.

[7] http://www.polytec.com/fileadmin/user_uploads/Products/ Vibrometers/PSV-500/documents/OM_DS_PSV-500_2012_ 09_3000_E.pdf.

[8] B. Köhler, "Dispersion relations in plate structures studied with a scanning laser vibrometer," in Proceedings of the 9th European Congress on Non-Destructive Testing (ECNDT '06), Paper no. 2.1.4, pp. 1-11, 2004.

[9] N. S. B. Muhammad, T. Hayashi, M. Murase, and S. Kamiya, "Analysis of guided wave propagation by visualizing in-plane and out-of-plane modes," in AIP Conference Proceedings, vol. 1096, pp. 774-781, 2008.

[10] P. Castellini, M. Martarelli, and E. P. Tomasini, "Laser Doppler Vibrometry: development of advanced solutions answering to technology's needs," Mechanical Systems and Signal Processing, vol. 20, no. 6, pp. 1265-1285, 2006.

[11] B. Pouet, S. Breugnot, and P. Clémenceau, "An innovative interferometer for industrial laser ultrasonic inspection," in AIP Conference Proceedings, vol. 760, pp. 273-280, 2005.

[12] T. Blum, B. Pouet, S. Breugnot, and P. Clémenceau, "Nondestructive testing using multi-channel random-quadrature interferometer," in AIP Conference Proceedings, vol. 975, pp. 239-246, 2008.
[13] M. Ruzzene, "Frequency-wavenumber domain filtering for improved damage visualization," Smart Materials and Structures, vol. 16, no. 6, pp. 2116-2129, 2007.

[14] M. Radzieński, L. Doliński, M. Krawczuk, A. Zak, and W. Ostachowicz, "Application of RMS for damage detection by guided elastic waves," Journal of Physics: Conference Series, vol. 305, no. 1, Article ID 012085, pp. 1-11, 2011.

[15] http://www.quantel-laser.com/tl_files/client/MY\%20QUANTEL\%20SPACE/Sales\%20Literature/CFR_Specs_EN_072012 .pdf. 

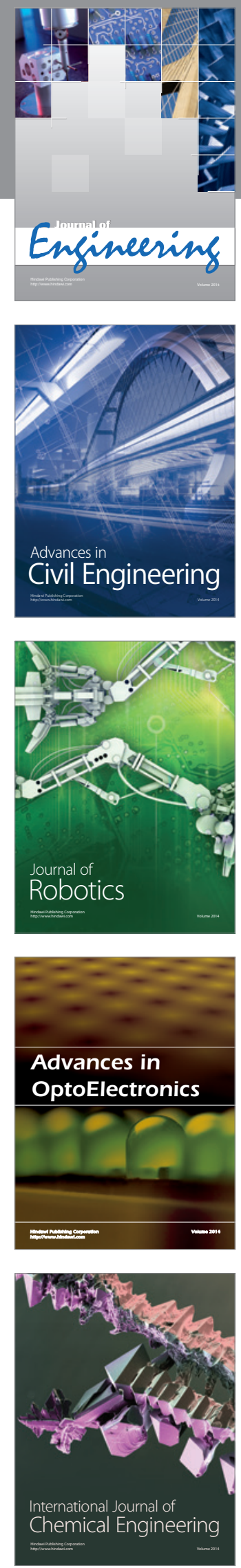

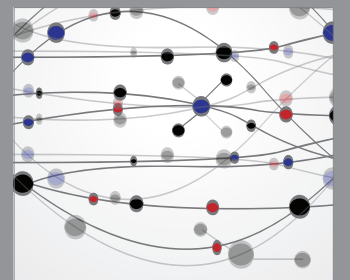

The Scientific World Journal
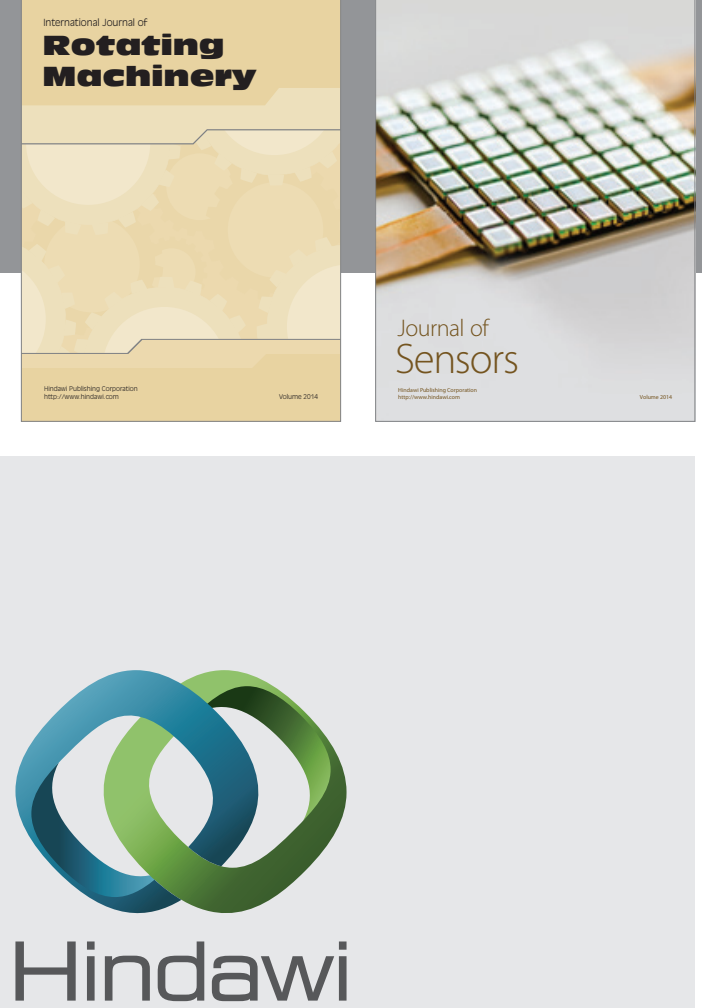

Submit your manuscripts at http://www.hindawi.com
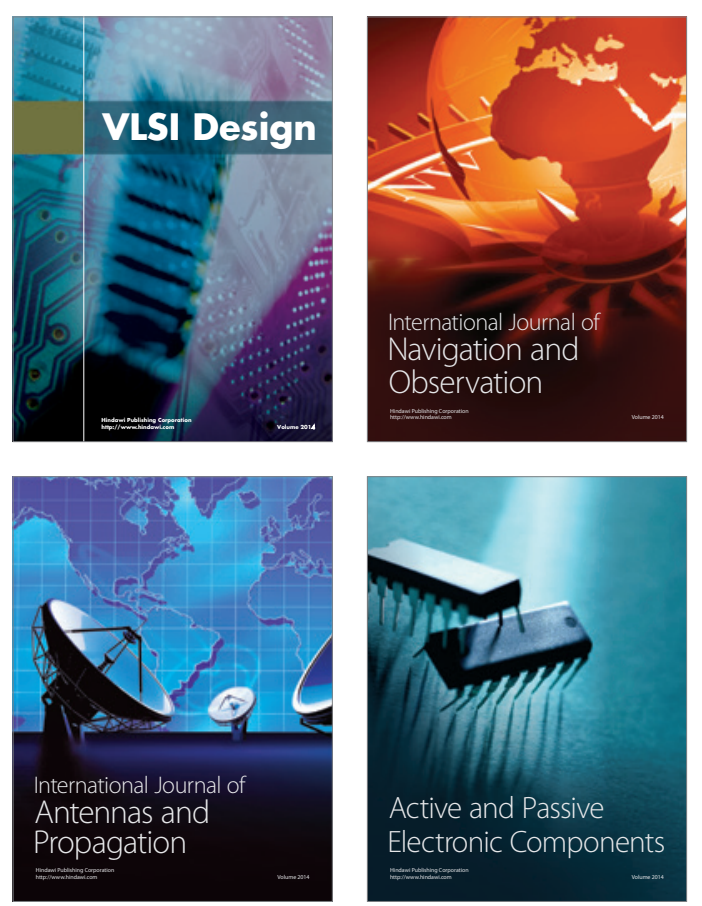
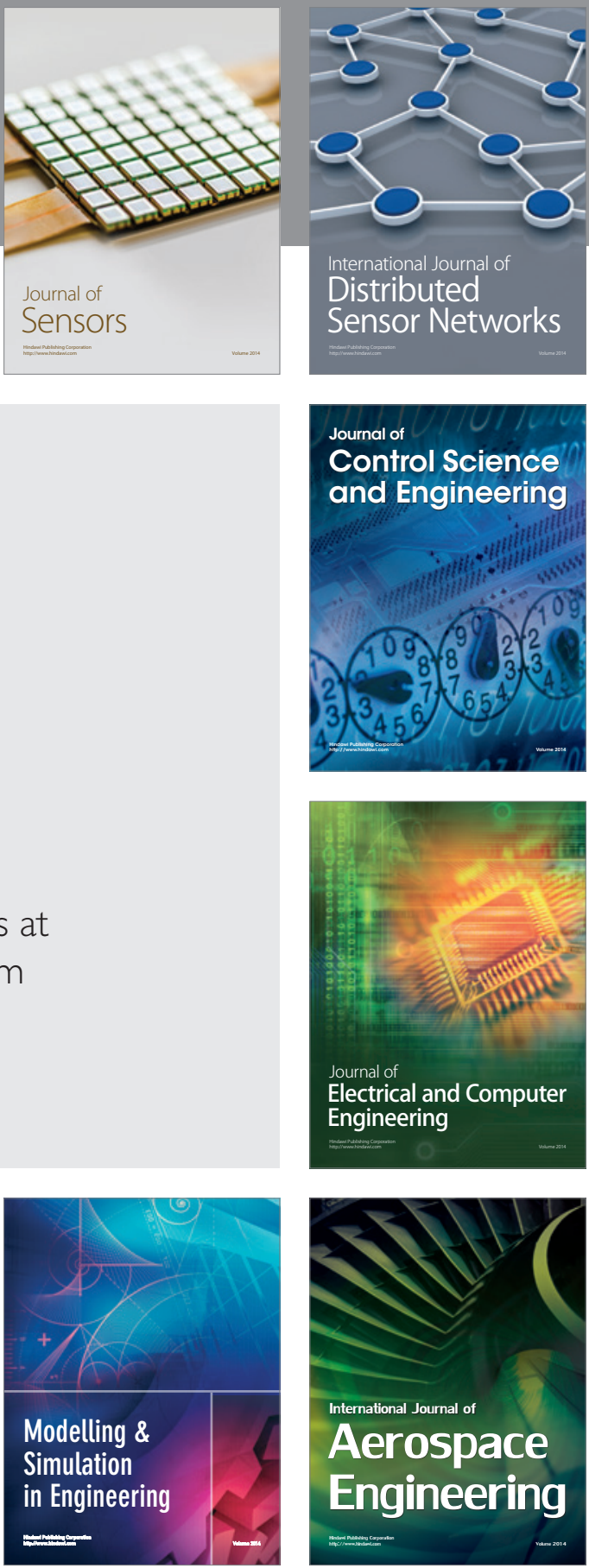

Journal of

Control Science

and Engineering
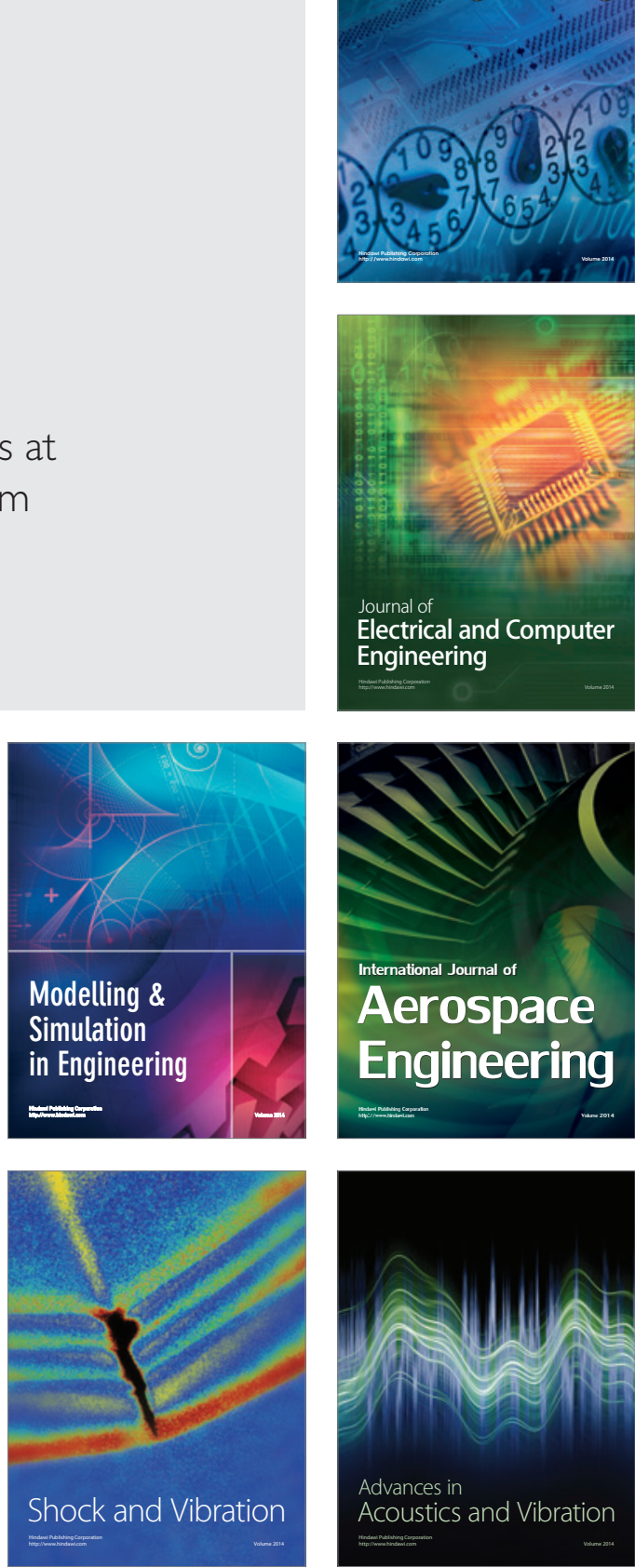